\title{
Temporal Signatures of Taste Quality Driven by Active Sensing
}

\author{
Dustin M. Graham, Chengsan Sun, and David L. Hill \\ Department of Psychology, University of Virginia, Charlottesville, Virginia 22904-4400
}

\begin{abstract}
Animals actively acquire sensory information from the outside world, with rodents sniffing to smell and whisking to feel. Licking, a rapid motor sequence used for gustation, serves as the primary means of controlling stimulus access to taste receptors in the mouth. Using a novel taste-quality discrimination task in head-restrained mice, we measured and compared reaction times to four basic taste qualities (salt, sour, sweet, and bitter) and found that certain taste qualities are perceived inherently faster than others, driven by the precise biomechanics of licking and functional organization of the peripheral gustatory system. The minimum time required for accurate perception was strongly dependent on taste quality, ranging from the sensory-motor limits of a single lick (salt, $\sim 100 \mathrm{~ms}$ ) to several sampling cycles (bitter, $>500 \mathrm{~ms}$ ). Further, disruption of sensory input from the anterior tongue significantly impaired the speed of perception of some taste qualities, with little effect on others. Overall, our results show that active sensing may play an important role in shaping the timing of taste-quality representations and perception in the gustatory system.
\end{abstract}

\section{Introduction}

Animals acquire information about their environment through active sensing. Rodents use rapid stereotyped behaviors such as sniffing and whisking to sample olfactory and tactile stimuli, with neural activity in these systems precisely aligned to the cycles of sampling behavior (Hill et al., 2011; Shusterman et al., 2011; Wachowiak, 2011). In the gustatory system, taste stimuli are sensed through the active process of licking, a rapid and stereotyped behavior that is the gustatory analog of sniffing in olfaction (Travers et al., 1997). During licking, taste stimuli are actively pulled into the mouth by the animal, creating a natural and sequential flow of information beginning from the tip of the tongue and following throughout the oral cavity (Reis et al., 2010). Although a prerequisite for tasting, the role of licking in shaping sensory processing in the gustatory system is poorly understood due in part to the use of a variety of experimental methods for delivering liquid taste stimuli that circumvent or alter the natural sequence of events associated with licking and active sensing (Katz et al., 2002b; MacDonald et al., 2009). Injection of liquid stimuli into the mouth of alert animals via intra-oral cannulas (IOCs) or pressurized lick spouts provides a rapid and reliable method of stimulus delivery for studying taste coding and perception. However, pressurized lick spouts and IOCs add a degree of passivity into the active process of tasting, potentially obscur-

Received Jan. 14, 2014; revised April 1, 2014; accepted April 11, 2014.

Author contributions:D.M.G. and D.L.H. designed research;D.M.G. and C.S. performed research;D.M.G. analyzed data; D.M.G. and D.L.H. wrote the paper.

This work was supported by the National Institutes of Health (Grants R01 DC00407 and F32 DC012461). We thank members of the Hill laboratory, Peter Brunjes, and Michael Long for fruitful discussions of the work and Alfredo Fontanini for critiquing an earlier version of the manuscript.

The authors declare no competing financial interests.

Correspondence should be addressed to Dustin M. Graham, Department of Neurobiology and Behavior, Life Sciences 573, SUNY at Stony Brook, Stony Brook, NY 11794-5230. E-mail: Dustin.Graham@stonybrook.edu.

DOI:10.1523/JNEUROSCI.0213-14.2014

Copyright $\odot 2014$ the authors $\quad 0270-6474 / 14 / 347398-14 \$ 15.00 / 0$ ing important aspects of gustatory sensory processing. Unlike other sensory systems that transmit information from the receptor organ to the brain through a single nerve, neural information about taste is brought into the brain by three separate nerves with anatomically and functionally distinct receptive fields (Shingai and Beidler, 1985; Spector and Travers, 2005; Spector and Glendinning, 2009). Therefore, passive stimulation could significantly affect the temporal sequence of receptive field activation and the downstream processing of taste information leading to perception. In the present study, we sought to understand the impact of active sensing on the timing of taste-quality perception in mice. Compared with previous studies measuring the speed of tastequality perception, our goal was to move beyond simply answering the question, "how fast is taste?" (Halpern and Tapper, 1971; Weiss and Di Lorenzo, 2012; Perez et al., 2013). Rather, we tested to determine whether specific taste qualities are perceived inherently faster than others during active sensing. Observing differences in the timing of perception of different taste qualities requires a task that has sufficient temporal resolution for measuring taste-guided decisions. To this end, we developed a novel taste-quality discrimination paradigm in head-restrained mice that enabled us to measure reaction times at the sensory-motor limits of a single lick under conditions mimicking fully active sampling behavior without pressurized delivery of stimuli. We found substantial differences in the timing of perception among basic taste qualities, forming a hierarchy of quality-specific temporal signatures. We also show here that the functional organization of the peripheral gustatory system, combined with licking, may provide a key mechanism in generating quality-specific differences in the timing of perception.

\section{Materials and Methods}

Subjects. Adult $(\geq 20 \mathrm{~g})$ female mice were used for all experiments. C57BL/6 mice $(n=10)$ were obtained from Charles River Laboratories. $\mathrm{P} 2 \mathrm{X} 2 / \mathrm{X} 3$ knock-out transgenic mice $(n=2)$ were received from Dr. 


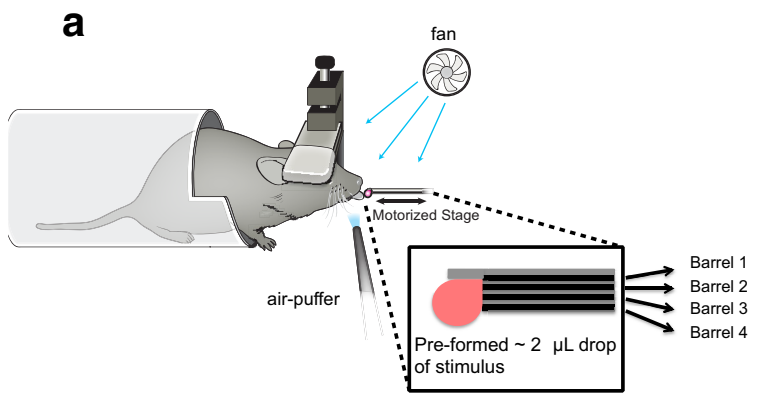

b
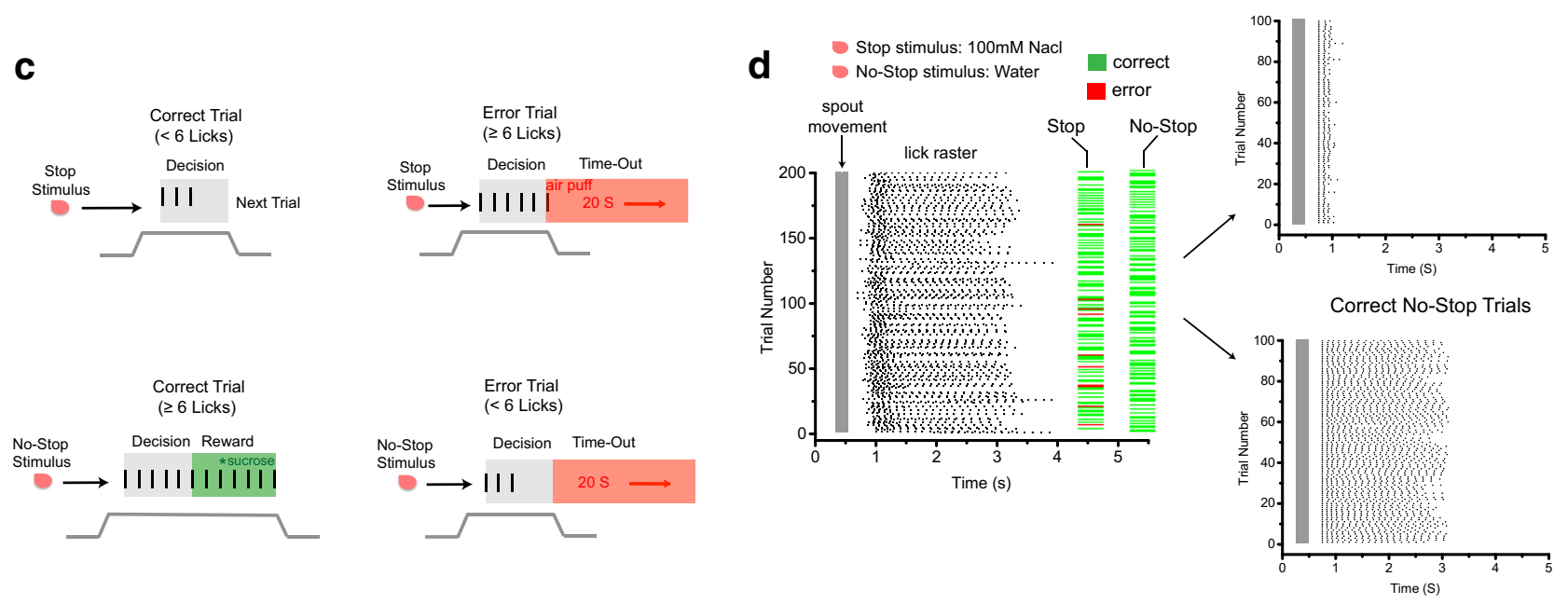

Figure 1. Gustatory stop-signal task in head-restrained mice. $\boldsymbol{a}$, Schematic of the apparatus for the gustatory stop-signal task. Inset shows the custom-made multibarrel lick spout with the individual barrels aligned and encased in dental cement to form a small well capable of holding $\sim 2 \mu \mathrm{l}$ of preformed stimuli. A fan above the lick spout is used to eliminate any potential olfactory cues from the taste stimuli. A small air-puff valve is placed near the whiskers for task reinforcement during stop-trial errors. $\boldsymbol{b}$, Schematic of the general structure of the gustatory stop-signal task. Before moving into licking position, an $\sim 2 \mu \mathrm{l}$ stimulus is preformed in the well of the lick spout tip. After moving into lick position, a brief tone is played to alert mice that a trial has begun. After the tone, mice have $3 \mathrm{~s}$ to decide to participate in a trial by initiating licking; otherwise, the lick spout retracts and is cleaned with a $20 \mathrm{~s}$ time-out period ensuing. After the first lick is registered on a trial, mice enter a $700 \mathrm{~ms}$ decision phase (light gray box) during which they must choose to continue or stop licking the lick spout depending on the stimulus quality (see Table 1 for stop and no-stop stimuli). Mice then enter a reward/punishment phase (dark gray box) depending on the trial type and performance during the preceding decision phase. c, Specific trial types and outcomes of the gustatory stop-signal task. Trial types are separated into stop and no-stop, with correct and error outcomes for both types. On correct-stop trials, mice must stop licking before reaching six licks after stimulus contact to avoid punishment. On stop-trial errors, mice fail to stop licking and reach at least six licks in the decision phase, causing a light air puff to the whiskers, spout retraction, and a $20 \mathrm{~s}$ time-out punishment. On correct no-stop trials, mice must reach $\geq 6$ licks in the $700 \mathrm{~ms}$ decision phase to then move into the reward phase during which they must execute an additional 2 licks in $500 \mathrm{~ms}$ (8 licks total) to receive an extra $\sim 2 \mu \mathrm{l}$ drop of sucrose for consumption. On no-stop trial errors, mice fail to reach six licks in the $700 \mathrm{~ms}$ decision phase, causing spout retraction and a $20 \mathrm{~s}$ time-out punishment. $\boldsymbol{d}$, Raster plot of licks during a full example session in a well trained mouse, with trial type and outcome aligned to each trial. To see the difference in behavior during different trial types clearly, the first 100 correct stop and no-stop trials were plotted separately, with each trial aligned by the first lick. Note the clear change in licking behavior during stop trials and the consistent unabated licking during correct no-stop trials.

Debra Cockayne (Hoffmann-La Roche, Nutley, NJ) and bred in-house. All mice were kept on a 12:12 light:dark cycle and given ad libitum access to water and rodent chow before behavioral training. We used separate groups of mice for the detection and discrimination versions of the stopsignal task ( $n=3$ for each group). For control experiments, to determine the exclusive use of taste for task performance, we used C57BL/6 $(n=2)$ and P2X2/X3 knock-out mice $(n=2)$. For bilateral chorda tympani transection experiments, we used the same mice $(n=3)$ trained in the detection version of the stop-signal task, as well as separate sham surgery control animals $(n=2)$. All methods used were approved by the University of Virginia Animal Care and Use Committee and conformed to National Institutes of Health's Guide for the Care and Use of Laboratory Animals.

Head-plate surgery and water scheduling. Mice were anesthetized with isoflurane (5\% induction, $1.5 \%$ throughout surgery) with surgical depth of anesthesia checked by lack of a reflex to light toe pinch. Body temperature was maintained at $37^{\circ} \mathrm{C}$ with a water heating pad. Mice were placed in a stereotaxic holder using a snout frame and a local injection of buprenorphine was made into the scalp. The skull was exposed with a small incision to the scalp and positioned so the dorsal surface of the skull and suture landmarks (bregma and lambda) were flat and even. A lightweight $(\sim 0.5 \mathrm{~g})$ head plate was affixed to the skull using photo-curing bonding agent and dental cement. After surgery, mice were placed back in their home cages and monitored until they were mobile and resumed normal activity, typically in $\leq 30 \mathrm{~min}$. After $48 \mathrm{~h}$ of recovery from head-plate surgery, water bottles were taken out of the cages and mice were placed on a $1.5 \mathrm{ml} / \mathrm{d}$ water restriction schedule. Mice received $1.5 \mathrm{ml}$ of water dispensed with a pipette in a small, custom-made stainless steel bowl $\sim 1-3 \mathrm{~h}$ after lights on for 7-10 d. Body weight was monitored daily and supplemental water was given as necessary to ensure that mice maintained $\geq 85 \%$ of their presurgical bodyweight.

Task apparatus. Mice were placed on a raised aluminum platform covered with a square piece of aluminum foil and a paper towel lightly dampened with tap water to ground the animal for lick monitoring with the lickometer (Fig. 1a). The head plate was locked into a c-clamp (Siskiyou) attached to a rigid metal post anchored to the table with a magnet (Thorlabs). The body of the animal was covered with a custom-cut halfpipe of PVC tubing that provided a protective environment without stressful constriction. Each mouse was positioned in a comfortable crouching position and the multibarrel lick spout was adjusted to individual height. The lick spout consisted of five stainless steel hypodermic tubes (25 gauge) cemented together with photo-curing dental cement (Fig. 1a). All five tubes were positioned in parallel and aligned with dental cement carefully shaped to encase the tips without covering them, creat- 


$\begin{aligned} & \text { Table 1. Stimuli used for stop and no-stop trials for discrimination and detection } \\
& \text { versions of the gustatory stop-signal task }\end{aligned}$
\begin{tabular}{lll} 
& Stop stimuli (mM) & No-stop stimuli (mM) \\
\hline Discrimination & NaCl: 100,50 & Sucrose: 300,100 \\
& Citric acid: 20,10 & \\
& QHCl: 1,2 & \\
& Distilled water & \\
& NaCl: 100,50 & Distilled water \\
Citric acid: 20,10 & \\
Detection & QHCl: 1,2 & \\
\end{tabular}

ing a small central well at the bottom of the lick spout. Fluid in each barrel was controlled by separate solenoid valves driven by an eight-valve controller (Automate Scientific). Fluid reservoirs and solenoid valves were placed outside of the Faraday cage enclosure of the behavior apparatus inside a grounded sound attenuation chamber. Liquid stimuli were propelled by gravity flow, with the final stimulus volume in the well of the lick spout determined by the adjustable height of the reservoir and timing of solenoid valve opening. Approximately $2 \mu \mathrm{l}$ was used as a stimulus volume on all trials for each taste stimulus and sucrose reward because this approximates the volume consumed by a mouse in a single lick. Consistent $\sim 2 \mu \mathrm{l}$ volumes of stimulus and reward delivery were verified before each session. We used the junction-potential method of monitoring licking, which provides a direct measurement of tongue contact with the stimulus with high signal-to-noise ratio, no amplification, and no current injection, eliminating any potential "electric taste" artifacts (Hayar et al., 2006). A split BNC cable was sent to a digitizer for lick data collection during task performance. The core of the BNC cable was attached to a small wire wrapped around the cemented barrels of the lick spout and the shell of the BNC cable was attached to the aluminum foil square on the animal's platform. Lick-spout position was controlled via a motorized linear stage (Zaber Technologies). The lick spout was positioned in a no-lick position $\sim 6 \mathrm{~mm}$ away from the animal's mouth and then moved into a comfortable lick position just in front of the animal's mouth at the beginning of each trial. Total movement time of the lick spout for each trial was $250 \mathrm{~ms}$, which helped to ensure that mice did not begin drinking from the spout before it was in its final drinking position on each trial. A separate motorized linear stage controlled an aspiration needle positioned below the well of the lick spout for cleaning the well between trials. A small computer fan was positioned above the lick spout to minimize any olfactory cues arising from the preformed pools of liquid stimuli (Fig. 1a). Speakers inside the Faraday cage delivered constant background white noise to filter out valve clicks and a brief auditory cue ( $2 \mathrm{kHz}$ tone) for the start of each trial. A small, 20 gauge stainless steel tube connected to $\sim 10$ psi air pressure was positioned near the animal's whiskers to serve as a puffer valve to deliver air puffs on stop trial errors to reinforce the stop-signal task structure. The behavioral apparatus was controlled by custom-written routines in LabVIEW.

Head restraint adaptation and sucrose training. Mice were adapted to head restraint and drinking from the moveable lick spout over 7-14 d with sessions of increasing duration until they would sit comfortably for $\sim 1 \mathrm{~h}$ and drink from the lick spout consistently for 150-200 trials (Fig. 1). On the first day of training, mice were not given any water before being put in the apparatus to maximize motivation for drinking from the lick spout. No water was given after training sessions to encourage mice to consume all of their daily fluids during the task. During this training phase, mice received $300 \mathrm{~mm}$ sucrose as a taste stimulus and reward. A $\sim 2$ $\mu \mathrm{l}$ drop of sucrose was preformed on the spout for each trial, with an additional $\sim 2 \mu \mathrm{l}$ drop of sucrose delivered after mice licked the spout 8 times. No temporal constraints were placed on licking to receive the reward, allowing mice to freely lick at whatever rate they chose. This enabled us to observe baseline sampling behavior without any potential affects due to the stop-signal task structure (see next section). Because of the water restriction and palatability of $300 \mathrm{~mm}$ sucrose, mice typically performed 150-200 trials during their first training session. Over the following 10-14 d, we gave mice gradually increasing amounts of presession water, in $0.25 \mathrm{ml}$ increments, $\sim 1 \mathrm{~h}$ before their daily training session until they performed $<150$ trials in an $\sim 1 \mathrm{~h}$ session. Once reaching this point, presession water was dropped by $0.25 \mathrm{ml}$ increments until mice began consistently performing 150-200 trials again. This final amount of presession water, which ranged between 0.5 and $2 \mathrm{ml}$ for each animal, was then given $\sim 1 \mathrm{~h}$ before all further sessions, including during the gustatory stop-signal task (see next section). This ensured that mice were at their most satiated state while still being sufficiently motivated to perform $\sim 200$ trials in a given session.

Gustatory stop-signal task structure. To quantify the speed of tastequality identification, we designed a novel reaction-time taste-quality discrimination paradigm using our head-restraint behavioral apparatus (Fig. 1b). The general task structure is as follows. At the beginning of each trial and before lick spout movement, an $\sim 2 \mu$ l stimulus was preformed inside the well at the tip of the lick spout. The spout was then rapidly moved into lick position with a brief auditory cue playing at the end of movement to alert the animal that a trial had begun. After the auditory cue, mice were given $3 \mathrm{~s}$ to choose to participate in the trial by initiating licking. If mice failed to initiate a lick within the $3 \mathrm{~s}$ interval, the lick spout retracted and animals were given a $20 \mathrm{~s}$ time-out. When the first lick was registered, mice entered a $700 \mathrm{~ms}$ decision phase during which they were required to decide to continue licking or stop licking within six licks, depending on the stimulus quality signaling different trial types (Fig. 1b). Specific trial types and outcomes were as follows. No-stop trials required mice to maintain licking during the decision phase (Fig. 1c). On correct no-stop trials, mice had to reach at least six licks within the $700 \mathrm{~ms}$ decision phase to then enter the reward phase. During the reward phase, mice were required to make an additional 2 licks within $500 \mathrm{~ms}$ to then receive an $\sim 2 \mu \mathrm{l}$ drop of sucrose reward from the lick spout. Upon reward delivery, mice were given $1.5 \mathrm{~s}$ to consume the reward before lick spout retraction. On error no-stop trials, mice failed to reach six licks during the decision phase, causing lick-spout retraction and a $20 \mathrm{~s}$ timeout punishment (Fig. 1c). Stop trials required mice to stop licking during the decision phase. On correct-stop trials, mice stopped or paused their licking sufficiently before reaching six licks in the decision phase, the lick spout retracted, and the next trial began without delay. On error-stop trials, mice failed to stop licking before six licks, causing a brief air puff (10 psi) to the whiskers to reinforce the task structure, lick spout retraction, and a $20 \mathrm{~s}$ time-out punishment. To ensure that stopping behavior during correct-stop trials represented true decisions and not pausing, which could occur with animal licking, we chose the parameters of the decision phase ( 6 licks in $700 \mathrm{~ms}$ ) to closely match the maximum lick rate mice naturally sampled during sucrose training $(9-10 \mathrm{~Hz})$. Therefore, to get no-stop trials correct, mice had to maintain close to their maximum natural lick rate. We found that, throughout all behavior experiments with this task structure, mice maintained their naturally fast $(9-10 \mathrm{~Hz})$ and low-variability licking behavior (i.e., no pausing; Fig. 1d). Mice were given $5-7 \mathrm{~d}$ to learn the initial task structure with $100 \mathrm{~mm} \mathrm{NaCl}$ as a stop stimulus and $300 \mathrm{~mm}$ sucrose or water used as no-stop stimuli for discrimination and detection tasks, respectively. When switching to a new stop stimulus quality (i.e., sour or bitter), mice were given $2-3 \mathrm{~d}$ to become familiar with the new stimulus quality and then $2-3 \mathrm{~d}$ of testing for analysis.

Reaction-time estimation. We relied on the cessation of action to estimate when mice made a decision about a taste stimulus during correctstop trials. An estimation of reaction time on correct-stop trials was calculated as the interval between the beginning of the first lick and the beginning of the estimated first absent lick (see Fig. $3 d$ for an example). The first absent lick was estimated using the average interlick interval (ILI) across all correct no-stop trials for all animals and sessions (62 \pm 1.2 $\mathrm{ms}$, mean $\pm \mathrm{SEM}$ ). Because licking during the decision phase of correct no-stop trials had low variability (see distribution of ILIs in Fig. $3 c$ ), we could confidently predict when the next lick would have occurred during a correct-stop trial.

Taste stimuli. Taste stimuli were prepared daily using distilled water. For discrimination tasks, stimuli were as follows (in $\mathrm{mM}$ ): no-stop, 300 and 100 sucrose; stop, 50 and $100 \mathrm{NaCl}, 10$ and 20 citric acid (CA), 1 and 2 quinine hydrochloric acid ( $\mathrm{QHCl})$. The same stop stimuli were used in the detection versions of the task, with distilled water used as the no-stop stimulus. For experiments to determine whether mice could use the lack 
of sucrose during stop trials as a discriminatory cue, we used distilled water as a stop stimulus and $300 \mathrm{~mm}$ sucrose as the no-stop stimulus. Concentrations were chosen to match the relative intensities of each quality. The concentrations used in this study also represent the most commonly used stimuli in studying the gustatory system in awake behaving rodents, allowing our results to be compared directly with previous work.

Brief-access testing with head-restrained mice. To estimate the time course required for mice to respond behaviorally to bitter taste stimuli, we developed a brief-access test for head-restrained mice using the same apparatus and head restraint described for the gustatory-stop signal task. Mice were kept on the same water schedule used for the stop-signal task. Instead of a $700 \mathrm{~ms}$ decision phase, mice were given $3 \mathrm{~s}$ to drink from the lick spout after initiating licking. Each recorded lick delivered an $\sim 2 \mu \mathrm{l}$ drop of stimulus in addition to the preformed stimulus before spout movement. We relied on the naturally aversive nature of the bitter stimuli used to drive changes in licking. Stimuli were $0.1,1$, and $2 \mathrm{~mm} \mathrm{QHCl.}$ During each session, water and a single concentration of quinine were used. Water and quinine were presented in a pseudorandom order. When mice no longer reached $\geq 15$ licks during water trials, they were considered satiated and the session was terminated. To measure changes in lick behavior to increasing concentrations of quinine across sessions, we counted the number of licks during the $3 \mathrm{~s}$ of licking for water and a given concentration of quinine and plotted them as a ratio (quinine/ water). Data are plotted as mean \pm SEM, with significant differences determined by Student's $t$ test ( $p \leq 0.5$ ). To estimate the average time for mice to detect the presence of quinine, we calculated the lick rate for water and the given concentration of quinine in $250 \mathrm{~ms}$ nonoverlapping windows using the first window with a significant divergence as the time of perception.

Chorda tympani transections. The three wild-type C57BL/6 mice trained in the detection version of the stop-signal task were used as subjects for the chorda tympani transection (CTx) experiments. Two days before CTx surgery, mice were taken off of the stop-signal task water schedule and given ad libitum access to water to fully hydrate themselves. Mice were sedated with an intramuscular injection of $0.32 \mathrm{mg} / \mathrm{kg}$ Domitor (medetomidine hydrochloride; Pfizer Animal Health) and anesthetized intramuscularly with $40 \mathrm{mg} / \mathrm{kg}$ Ketaset (ketamine hydrochloride; Fort Dodge Animal Health). Body temperature was maintained with a water-circulating heating pad. After positioning in a nontraumatic head holder, a ventral approach was taken to expose and cut the chorda tympani nerve. After both nerves were cut, the incision was closed with sutures and an intramuscular injection of $1.6 \mathrm{mg} / \mathrm{kg}$ Antisedan (atipamezole hydrocholoride; Pfizer Animal Health) was given to reverse anesthesia. For sham animals, the same surgical approach was taken with the exception that the nerves were not sectioned.

Data analysis. Lick data were digitized at $1 \mathrm{kHz}$ sampling frequency with an eight-channel digitizer (PowerLab; AD Instruments). We simultaneously measured the analog output of the eight-valve solenoid controller as a marker of stimulus and trial type. For comparing taste-quality discrimination and detection speeds, we used data from two to three sessions for each animal for each taste quality tested $(\sim 600-800$ trials total for each taste quality). To ensure that mice were at similar motivational states for reaction-time measurements, we measured ( post hoc) the fraction of no-stop trials mice performed correctly in rolling 10 trial windows. Once mice fell below $80 \%$ correct no-stop trials, they were deemed satiated and further trials in a given session were removed from further analysis. Only sessions in which mice performed a minimum of 100 trials after normalizing for changes in motivation were used for analysis. Data processing, lick measurements, and statistical analysis were conducted using custom-written routines in LabVIEW and OriginPro. Task performance is presented as a fraction of correct trials. Data are plotted as mean \pm SEM, with statistical significance determined at $p<$ 0.05 using Student's $t$ test and one-way ANOVA with Bonferroni correction. Given that our reaction-time distributions were typically not normally distributed, we also conducted Kolmogorov-Smirnoff tests to establish statistical significance for differences in reaction-time distributions among taste qualities. The conclusions were identical to those presented using standard Student's $t$ tests of the means and one-way ANOVA testing.

\section{Results}

To study the speed of taste-quality perception in mice during active sampling, we developed a taste-quality perceptual decision-making task in head-restrained freely licking mice based on a modified stop-signal paradigm. The design of the task differs in several ways from extant rodent taste perception paradigms. Importantly, the head restraint and task apparatus allowed us to measure taste-quality-based decisions with high temporal resolution and to avoid pressurized delivery of taste stimuli. Using a multibarrel lick spout mounted on a motorized linear stage allowed us to use preformed $\sim 2 \mu$ l pools of liquid stimuli for sampling, recreating the natural and fully active process of mice pulling liquid stimuli into their oral cavity during licking (Fig. $1 a$ ). A single $\sim 2 \mu \mathrm{l}$ stimulus was used because it approximates the amount consumed by a mouse with a single lick (Hayar et al., 2006). Before training in the stop-signal task, mice were adapted to head restraint and drinking from the moveable lick spout using $\sim 2 \mu \mathrm{l}$ preformed pools of sucrose with no timing requirements on licking behavior. This allowed us to measure sampling behavior in motivated head-restrained mice without the influence of the experimental task structure. We found that mice sat comfortably for up to $1.5 \mathrm{~h}$ and naturally licked at a frequency of $9-10 \mathrm{~Hz}$ in a highly stereotyped fashion, similar to other studies (Glendinning et al., 2002; Hayar et al., 2006; Johnson et al., 2010). After $7-10 \mathrm{~d}$ of sucrose training, mice then began training in the stopsignal task. The general structure of the stop-signal task and specific trial types are shown in Figure $1, b$ and $c$. Trial types were segregated into stop or no-stop types, depending on the stimulus quality presented for sampling, with correct and error outcomes for each trial type. Mice received a single preformed $\sim 2 \mu \mathrm{l} \mathrm{stim-}$ ulus for sampling on each trial. After contacting the $\sim 2 \mu$ l pool of preformed stimulus with their first lick, mice had $700 \mathrm{~ms}$ and five licks to decide to either continue licking the dry spout without any significant pausing (no-stop stimulus) to receive a reward or to completely stop licking within five licks (stop stimulus) to avoid punishment (Fig. 1). Because stop stimuli ranged in palatability (appetitive to aversive) and concentration, stopping behavior on correct-stop trials was based on taste-quality identification, not innate preferences or stimulus intensity (see Fig. 4). We used stopping behavior on correct-stop trials as a measure of reaction time for the specific taste quality used as the stop stimulus during a given session (see Fig. $3 d$ and Materials and Methods). An example session, split into the first 100 correct stop and correct no-stop trials in a well trained mouse, is shown in Figure 1d.

\section{Gustatory stop-signal task is learned rapidly and requires taste}

Mice were first trained to distinguish $100 \mathrm{~mm} \mathrm{NaCl}$ from $300 \mathrm{~mm}$ sucrose, which are both palatable taste stimuli (Glendinning et al., 2002; Grobe and Spector, 2008). Mice quickly learned to stop licking when sampling $100 \mathrm{~mm} \mathrm{NaCl}$ within the decision phase of stop trials, with all mice reaching well above chance levels of performance during their first training session (Fig. 2a,b). After reaching a learning criterion of $80 \%$ correct performance, multiple concentrations of each taste quality were used in the following sessions to minimize stimulus intensity as a discriminatory cue (Spector et al., 1996; St John and Spector, 1998; Dotson and Spector, 2007). Even with minimized intensity cues, mice quickly reached $85-95 \%$ performance levels (Fig. $2 b$ ). To rule out the use 


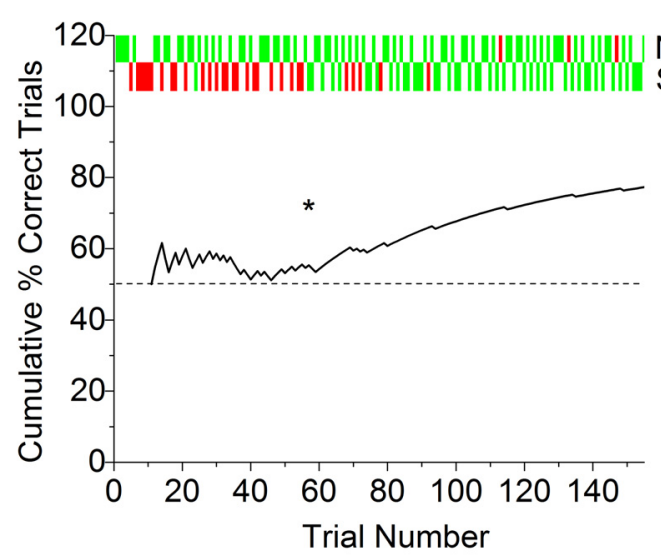

c

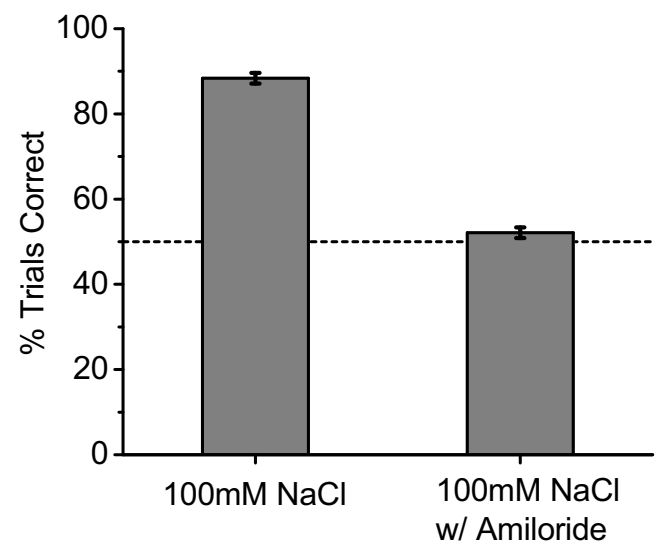

b

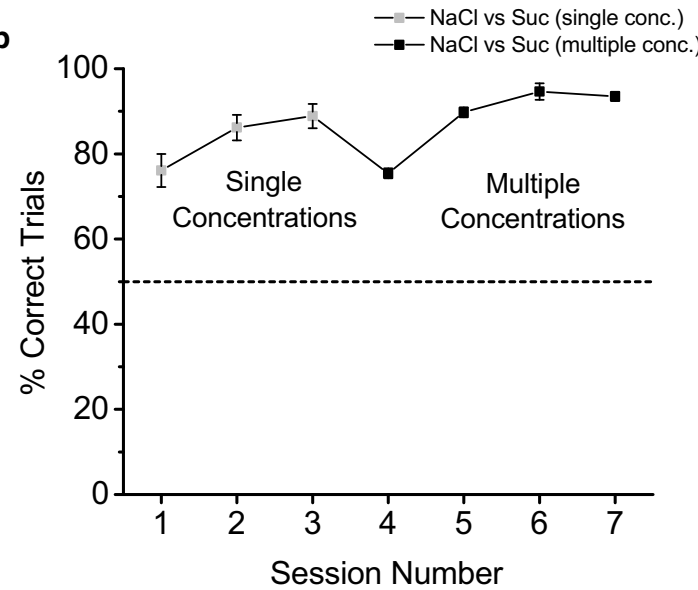

d

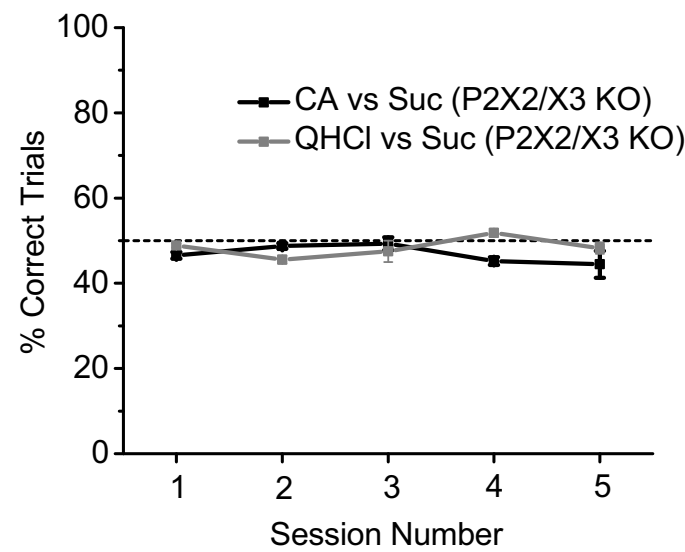

Figure 2. Gustatory stop-signal task is rapidly learned and requires taste. $\boldsymbol{a}$, An example of the first session of stop-signal task for one animal. A running average of performance (black line) is plotted with individual trial types and outcomes aligned and plotted at the top. Asterisk denotes when animal began to consistently perform correct-stop trials, indicating learning. Dashed gray line indicates $50 \%$ chance performance level. $\boldsymbol{b}$, Performance in gustatory stop-signal task across sessions for mice $(n=3)$ discriminating $100 \mathrm{~mm} \mathrm{NaCl}$ (stop stimulus) from $300 \mathrm{~mm}$ sucrose (no-stop stimulus). Data are plotted as mean \pm SEM. Note that each animal reached well above chance levels of performance during the first session. After performing above learning criterion ( $80 \%$ correct trials), the task was made more difficult by adding multiple concentrations of $\mathrm{NaCl}$ and sucrose for mice to discriminate (asterisk), minimizing intensity differences as a discriminatory cue. NaCl concentrations were 100 and $50 \mathrm{~mm}$ and sucrose concentrations were 300 and $100 \mathrm{~mm}$. Dashed line indicates $50 \%$ chance performance level. c, Performance of control mice $(n=2)$ in detecting 100 $\mathrm{mм} \mathrm{NaCl} \mathrm{from} \mathrm{distilled} \mathrm{water} \mathrm{in} \mathrm{stop-signal} \mathrm{task} \mathrm{with} \mathrm{and} \mathrm{without} 20 \mu \mathrm{m}$ amiloride added to the solutions. Data are plotted as mean \pm SEM. After 3 straight days of $\geq 80 \%$ correct performance, amiloride was added to the stimulus solutions and caused performance to drop to $50 \%$ chance levels, demonstrating that mice required the taste of salt to perform the NaCl detection stop-signal task. $\boldsymbol{d}$, Performance in stop-signal task (mean \pm SEM) across multiple sessions for taste-blind transgenic P2X2/X3 double knock-out mice $(n=2)$ with all other taste stimuli used in this study. Even with extended training, P2X2/X3 double knock-out mice could not discriminate between sour, bitter, or sweet taste stimuli above 50\% chance levels, indicating that taste sensation is required for learning and performing at high levels of accuracy in the gustatory stop-signal task. Stimuli were 10 and $20 \mathrm{~mm}$ citric acid (CA), 1 and 2 mm QHCl, and 300 and 100 sucrose (Suc).

of nongustatory cues for stop-signal task performance, we conducted control experiments with wild-type and transgenic "tasteblind" P2X2/X3 knock-out mice (Finger et al., 2005). As a control for the taste of salt, wild-type mice were initially trained in a salt-detection version of the task in which the no-stop stimulus was water and the stop stimulus was $100 \mathrm{~mm} \mathrm{NaCl}$. After reaching $>80 \%$ correct performance levels for $3-4 \mathrm{~d}$ in a row, these mice were tested in the same task but with $20 \mu \mathrm{M}$ amiloride added to the stimulus solutions to block sodium taste transduction in taste receptor cells (Heck et al., 1984; Hill et al., 1990; Chandrashekar et al., 2010; Oka et al., 2013). Amiloride dropped performance levels in mice to chance levels, demonstrating that mice required the taste of salt to perform the task (Fig. 2c). To test the potential use of nongustatory cues for the remaining taste qualities in the study, taste-blind P2X2/X3 double knock-out mice were trained to discriminate sucrose from citric acid and quinine. Even with extended training, P2X2/X3 double knock-out mice were unable to reach significantly above chance levels, further demonstrating that taste is required for performing the stop-signal task (Fig. 2d).

\section{Sampling behavior is not disrupted by the stop-signal task}

To ensure that the stop-signal task did not disrupt normal sampling behavior, we compared licking during correct no-stop trials in the stop-signal task with licking during sucrose training in the same animals. We measured the lick durations (LDs) and ILIs (ILI) of the first five licks for each trial, representing the decision phase of the stop-signal task. We found that licking behavior during correct no-stop trials was nearly identical to sucrose training (Fig. 3a), with distributions of LDs and ILIs for both conditions largely overlapping (Fig. 3b,c). Most importantly, we did not observe any long pauses or increases in variability in ILIs during the decision phase of correct no-stop trials, which would have manifested as a broadening of the distribution and made interpretation of correct-stop trials difficult. This result, combined with the overall low rate of no-stop trial errors $(1.7 \pm 0.4 \%$, mean \pm SEM $)$, strongly suggests that mice began each trial during the stop-signal task as a no-stop trial, launching into their natural licking behavior and stopping only when they had identified the stop stimulus. The low vari- 


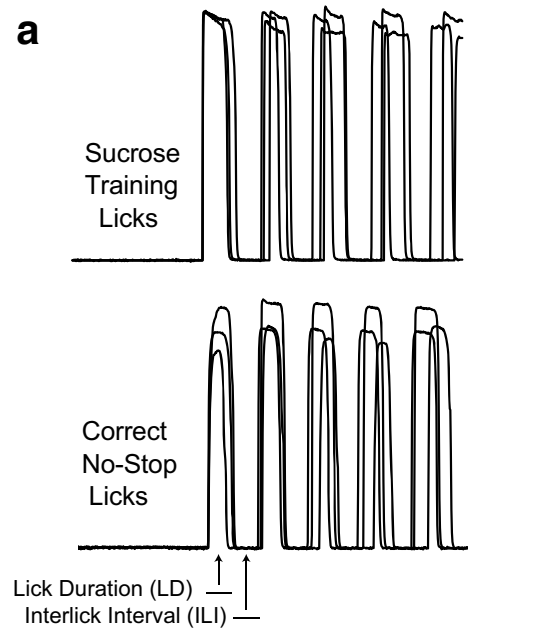

b

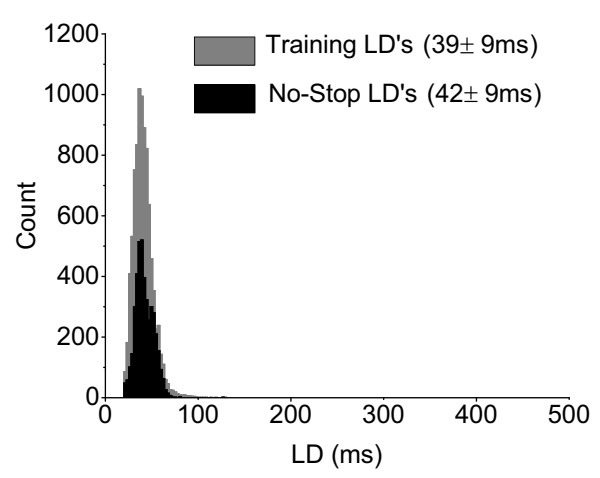

C

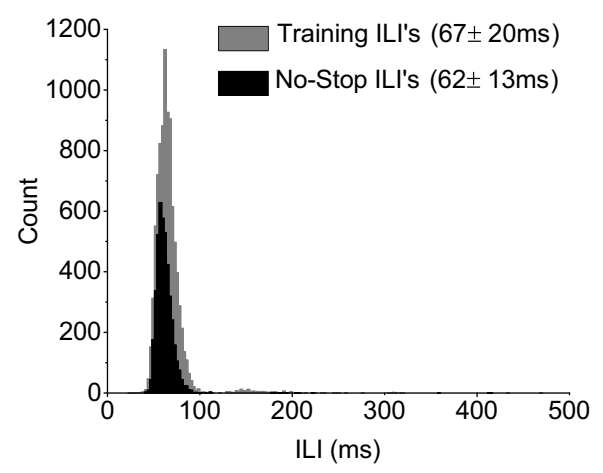

d

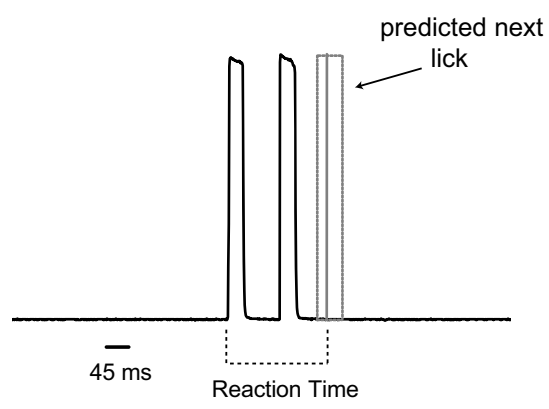

e

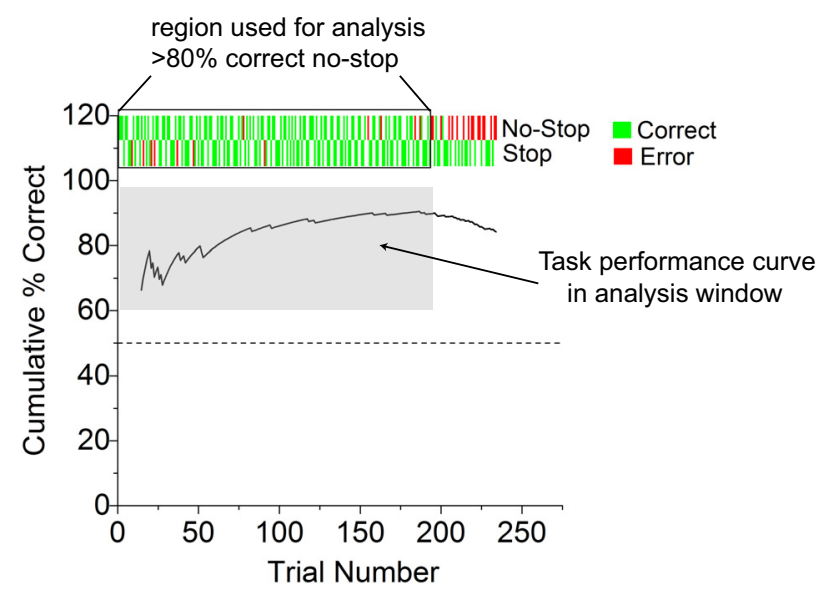

Figure 3. Mice maintain natural sampling behavior in stop-signal task. $\boldsymbol{a}$, Example raw lick data during sucrose training and correct no-stop trials in a well trained animal. Three randomly chosen trials for each condition are overlaid and aligned by the first lick to demonstrate the low variability in licking in both sucrose training and no-stop trial types. Definitions of $L D$ and ILI are shown. $\boldsymbol{b}$, c, Distributions of LDs and ILIs during sucrose training (gray) and correct no-stop trials (black). Largely overlapping distributions indicate that sampling behavior was left largely unaffected by the stop-signal task. Mean \pm SD for LD and ILI for each condition are shown. Jitter, defined as the SD, generally decreased for LDs and ILIs after training in the stop-signal task, indicating that licking became slightly more precise with training. $\boldsymbol{d}$, Raw lick data for a correct-stop trial demonstrating reaction-time measurement. Based on the distribution of ILIs from correct no-stop trials in $\boldsymbol{c}$, the next absent lick on a correct-stop trial can be accurately estimated at an average of $62 \mathrm{~ms}$ from the end of the last recording lick ( $62 \mathrm{~ms}$ mean, solid gray line; dashed gray box indicates $95 \%$ confidence interval). This time interval was added to all reaction-time measurements on correct-stop trials. $\boldsymbol{e}$, Example of a stop-signal task session in a well trained animal demonstrating how change in the animal's motivation is controlled for in reaction-time measurements. Only trials that occur when the animal is motivated to drink, defined by maintaining $\geq 80 \%$ correct no-stop trial performance in rolling 10 trial windows (outlined in black box), are used for data analysis. This ensures that the animal's performance during a correct-stop trial represents a decision and not simply unmotivated licking.

ability in licking during correct no-stop trials allowed us to confidently predict when the next lick would have occurred during a correct-stop trial (Fig. $3 d$ ), providing an upper bound on when the mouse had reached a decision and appropriately changed behavior. This served as our estimate of reaction time for each correct-stop trial. To further ensure the integrity of our reaction-time measurements during correct-stop trials, we only used trials for analysis during each session when mice remained motivated to drink, as judged by high levels of performance during no-stop trials (Fig. 3e). We used a criterion of $80 \%$ correct no-stop trials, measured in rolling 10 trial windows. As demonstrated in Figure $3 e$, trials (both stop and no-stop) that occurred after mice fell below the level of $80 \%$ correct no-stop trial performance were excluded from further analysis.

\section{Taste-quality perception at the sensory-motor limits} of gustation

To determine the resolution of our gustatory stop-signal task, we studied reaction times in mice trained to discriminate multiple concentrations of sucrose and $\mathrm{NaCl}$, which are representative stimuli of the basic taste qualities sweet and salty (Katz et al., 2002b; Carleton et al., 2010). Mice accurately identified the presence of salt with an average speed of $\sim 275 \mathrm{~ms}$, but were capable of correct decisions in a single lick, representing reaction times of $\sim 100 \mathrm{~ms}$ (Fig. 4a). Although the number of single-lick correctstop trials occurred with an average rate of $14.3 \%$ of total correctstop trials per session, this rate was significantly higher than the $1.7 \%$ average no-stop trial error rate per session $(p<0.00001)$, indicating that the single-lick reaction times represent true decisions and not anticipatory guessing (Fig. 4b). Therefore, our results demonstrate that mice are capable of correctly identifying salt from sugar at the sensory-motor limits of a single lick and that $\sim 100 \mathrm{~ms}$ provides sufficient information in the gustatory system for accurate discrimination of these two basic taste qualities. Why, then, do mice display such variability in their timing of taste-quality perception in the task? Reaction times in controlled tasks are stochastic, with variability arising from multiple sources, including sensory and motor components of the decision-making process and drifts in an animal's attention and 
a

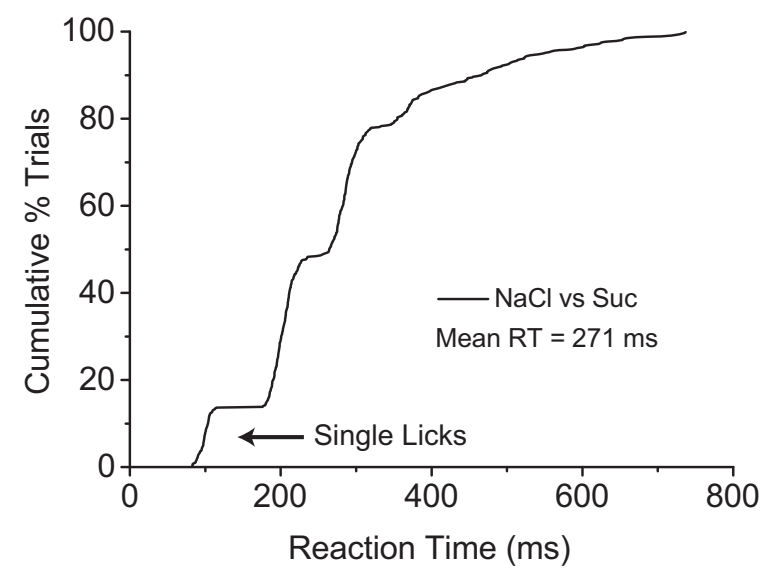

C

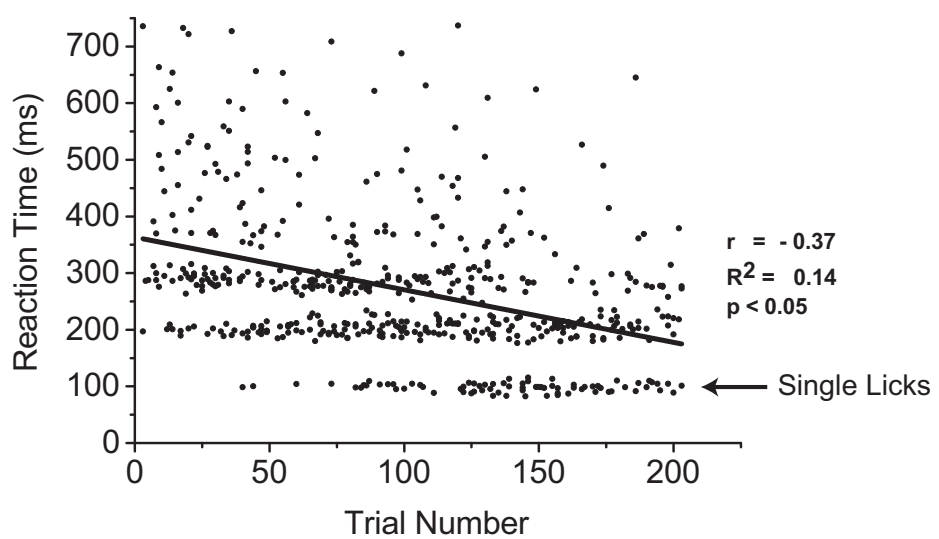

b

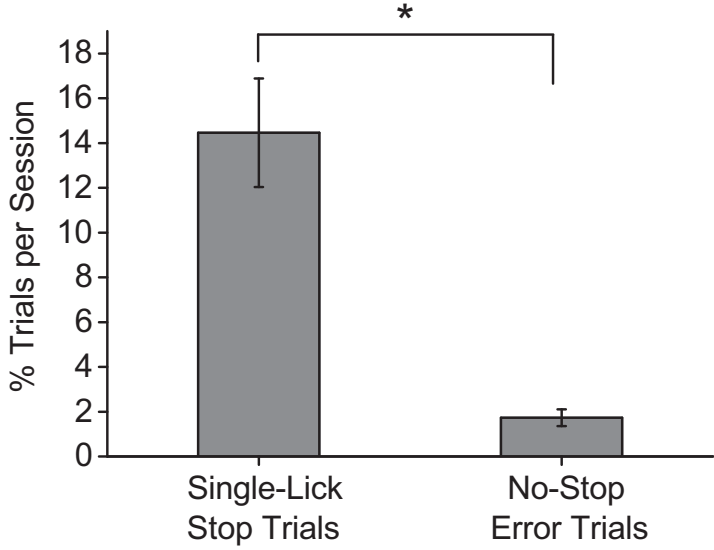

d

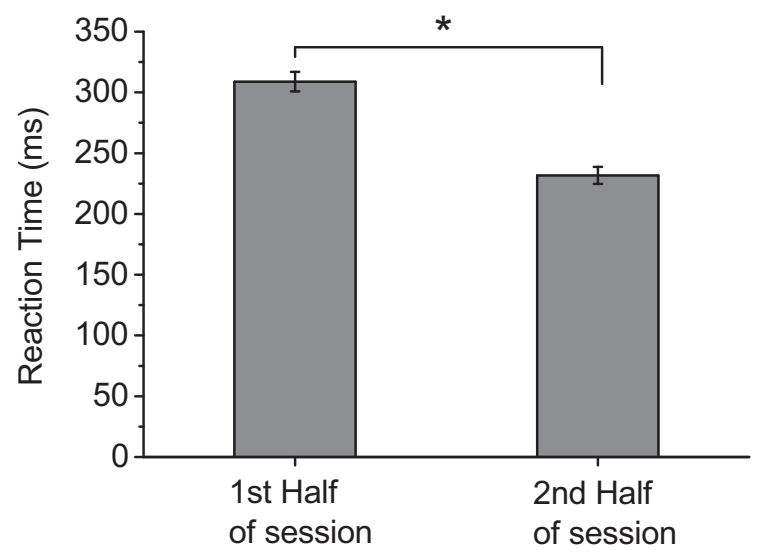

Figure 4. Mice can discriminate salt from sweet in a single lick ( $\sim 100 \mathrm{~ms}$ ). $\boldsymbol{a}$, Cumulative distribution of reaction times for correct-stop trials for mice discriminating between $\mathrm{NaCl}$ (stop) and sucrose (no-stop). Stimuli were 100 and $50 \mathrm{~mm} \mathrm{NaCl}$ and 300 and 100 mm sucrose. The average reaction time was $\sim 275$ ms, but mice were capable of stopping their licking to NaCl in a single lick (arrow), with reaction times of $\sim 100 \mathrm{~ms}$, indicating that neural activity in this time window is sufficient for accurate taste-quality identification. $\boldsymbol{b}$, Comparison of average rates of single-lick correct-stop trials and no-stop trial errors per session (mean \pm SEM). Mice performed significantly more single-lick correct-stop trials per session than no-stop trial errors, indicating that single-lick correct-stop trials reflect true decisions by the animal and not anticipatory guessing ( $p<0.00001, t$ test). c, Reaction times plotted against trial number show a significant negative correlation. This indicates that, as animals progressed further into a session, their reaction times became faster. This may be due to mice gaining more control over their licking behavior as they become less thirsty throughout a session. Most importantly, note the appearance of the majority of single-lick reaction times (arrow) toward the end of sessions. Single-lick reaction times, therefore, may represent the true sensory processing time needed to discriminate between $\mathrm{NaCl}$ and sucrose when motivation and motor control of licking are controlled for. $\boldsymbol{d}$, Comparison of reaction times in the first versus the second half of sessions, demonstrating a 46\% significant decrease in reaction time during the second half of sessions (mean \pm SEM, $p<0.00001, t$ test).

motivational state (Gold and Shadlen, 2007). Given the strong correlation between thirst and the ability of mice to control licking when consuming liquid stimuli, we propose that variability in reaction times measured in our task is accounted for in part by changes in an animal's motivation and ability to control the motor sequence for generating licking. We assumed that, despite no changes in the rate of correct no-stop trials, mice became less thirsty as a session progressed, attaining better control over their licking behavior. To test this hypothesis, we plotted the reaction times for all individual correct-stop trials against their trial number in a session. As can be seen in Figure $4 c$, we found a significant negative correlation between reaction time and trial number, suggesting that, as mice progressed through a session, their ability to control licking increased. Most notably, the majority of singlelick correct-stop trials did not begin until the latter half of each session (Fig. 4c). Consistent with these findings, we also observed a $46 \%$ decrease in average reaction time in the second half of each session ( $p<0.00001$; Fig. $4 d$ ). We found a small but significant increase in the average ILI $(3.82 \pm 0.81 \mathrm{~ms}$, mean \pm SEM) between the first and second half of each session, suggesting that mice may have become slightly more conservative in their sampling behavior during the second half of each session, but not enough to explain the $\sim 85 \mathrm{~ms}$ decrease in average reaction time. Overall, the data argue in favor of a motivational/motor origin for a significant amount of variability in reaction times and suggest that, despite occurring on only a small fraction of correct-stop trials, $\sim 100$ ms single-lick reaction times represent an accurate estimate of the minimum sensory processing time needed to make an appropriate decision between salty and sweet taste qualities in mice.

\section{Discrimination speed is taste-quality dependent}

With the knowledge that the gustatory stop-signal task can capture taste-quality discrimination at the maximum resolution of a single lick, we challenged mice to discriminate sucrose from other taste qualities using citric acid (sour) and quinine (bitter) stimuli as stop signals. Mice showed only small differences in their performance accuracy among salt, sour, and bitter taste qualities, but displayed a large difference in speed of taste-quality discrimination, with salt discrimination occurring $\sim 100 \mathrm{~ms}$ faster than sour or bitter $(p<0.0001$; Fig. $5 c)$. This indicates that, compared with 
a

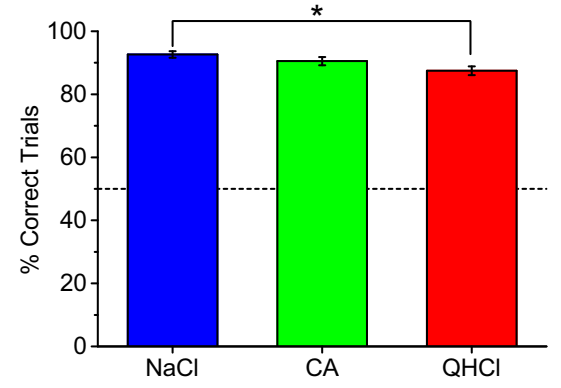

b

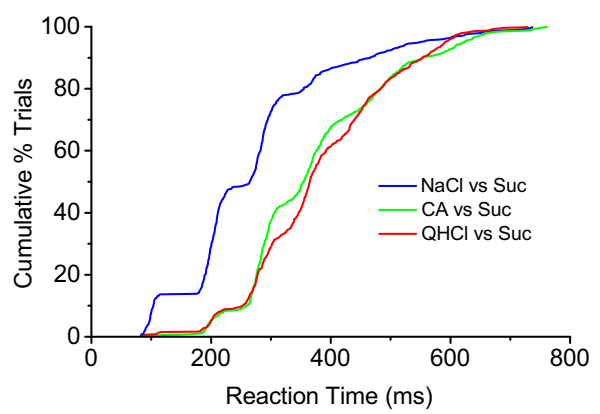

C

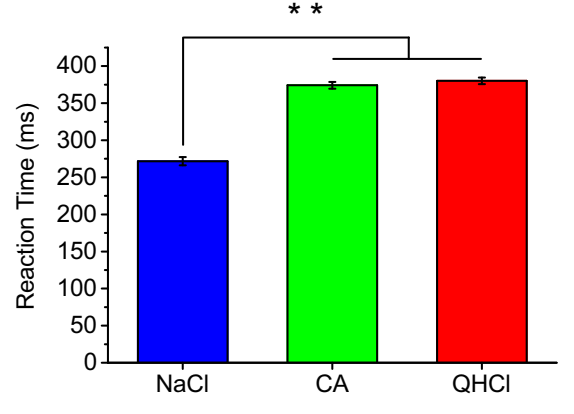

Figure 5. Quality-specific differences in speed of discrimination. $\boldsymbol{a}$, Comparison of performance discriminating sucrose (no-stop) from different taste qualities (stop). Stop stimuli were 100 and $50 \mathrm{~mm} \mathrm{NaCl}, 20$ and $10 \mathrm{~mm}$ citric acid (CA), and 1 and $2 \mathrm{~mm} \mathrm{QHCl}$. Mice performed well with all stop-signal taste qualities, with a slight but significant difference between NaCl and QHCl performance $(p<0.05$, ANOVA). Data are plotted as mean \pm SEM. Dashed line denotes $50 \%$ chance performance level. $\boldsymbol{b}$, $\boldsymbol{c}$, Cumulative distributions and mean \pm SEM of reaction times for different stop-signal taste qualities. Mice discriminated salt from sucrose $\sim 100 \mathrm{~ms}$ faster than citric acid or quinine from sucrose, which corresponds to a full sampling cycle longer for accurate identification of bitter and sour taste stimuli ( $p<0.001$, ANOVA). Unlike NaCl, mice never responded accurately in a stop trial with citric acid or quinine in a single lick. Statistical significance between conditions is indicated by asterisks.

salt, mice require a full sampling cycle longer to accurately identify sour and bitter from sweet. We observed that mice required a minimum of two licks during correct-stop trials with bitter and sour stimuli (Fig. 5b).

\section{Detection task reveals large difference in speed of bitter perception}

Differences in transduction cascades, stimulus intensity, and/or stimulus palatability most likely do not account for the significant differences in discrimination speeds between taste qualities seen in Figure 5. To determine a potential mechanism underlying the differences in discrimination speeds, we next tested mice in a detection version of the stop-signal task using the same set of stop stimuli (salt, sour, and bitter), but using distilled water as the no-stop stimulus. Comparing the speeds of salt and sour detection, we observed the same general trend seen in the discrimination version of the task, with mice responding significantly faster to salt than sour stimuli ( $p<0.0001$; Fig. $6 c)$, with a small but significant difference in overall task performance accuracy $(p<$ 0.001; Fig. $6 a$ ). However, the most striking finding was performance in bitter detection. Unlike bitter versus sucrose discrimination, mice were unable to perform above chance levels when challenged to detect bitter stimuli from water (Fig. $6 a, b$ ). There was no overall change in the animals' sampling behavior or motivation to engage in the task (Fig. $6 b$, top) and performance curves all trended toward chance levels during individual sessions (Fig. 6b). Even when the decision phase and stimulus volume was increased ( $\sim 4 \mu \mathrm{l}, 10$ licks in $1200 \mathrm{~ms}$ ), mice still performed only at chance levels when challenged to detect $2 \mathrm{mM} \mathrm{QHCl}$ from distilled water $(51.3 \pm 2.7 \%$ correct trials, mean \pm SEM $)$.

These results were surprising given the aversive nature of quinine at the concentrations used in the task and because mice were capable of performing at high levels of accuracy during the quinine versus sucrose discrimination task (Fig. 5). During the quinine versus sucrose discrimination task, mice must have exclusively used the absence of sucrose on stop trials as a cue to stop licking. We tested this assumption directly by using distilled water as the stop stimulus and $300 \mathrm{~mm}$ sucrose as the no-stop stimulus. Consistent with our hypothesis, the speed and accuracy of discriminating water from sucrose were both indistinguishable from discriminating quinine from sucrose ( $p>0.60$; Fig. 7$)$. Because mice were using the absence of sucrose, the reaction times shown in Figure 7 provide an estimate of the speed of sweet detection, placing it near the same speed as sour detection.

\section{Brief-access testing of quinine in head-restrained mice}

Because quinine at the concentrations used in the stop-signal task cause large changes in animal drinking behavior (Grobe and Spector, 2008), we wanted to ensure that the head-restrained mice used in our study were able to detect the presence of quinine. We developed a brief-access version of our paradigm using the same behavioral apparatus and water deprivation used in the stop-signal task. Head-restrained mice were given $3 \mathrm{~s}$ to freely drink from the multibarrel lick spout after the first lick on a trial was registered, with no decision phase or other task structure. On each trial, mice were given either distilled water or a single concentration of quinine that varied from session to session $(0.1,1$, or $2 \mathrm{~mm}$ ). Similar to the stop-signal task, a preformed $\sim 2 \mu$ l drop was used as the stimulus; however, each registered lick delivered an additional $\sim 2 \mu \mathrm{l}$ drop of stimulus throughout the 3 s drinking interval. Therefore, in addition to significantly increased sampling time, mice were able to sample significantly more stimulus volume during the brief-access test. We measured the ratio of licking to quinine over water for each concentration of quinine. As expected, we found that the ratio of quinine licking dropped significantly in a concentration-dependent manner, indicating that head-restrained mice in the behavioral apparatus were capable of detecting the presence of quinine at concentrations used in the stop-signal task $(p<0.01 ;$ Fig. $8 a)$. To estimate the amount of time required for mice to respond to the presence of quinine, we compared the average lick rate for water and quinine stimuli, moving in nonoverlapping $250 \mathrm{~ms}$ time windows (Fig. 8b,c). We used the first time window of significant divergence in lick rate as an estimate of when the mice became aware of the presence of quinine. We found that, for both 1 and $2 \mathrm{~mm}$ concentrations of quinine, lick rate did not significantly diverge until $\sim 750 \mathrm{~ms}(p<$ 0.00001 ; Fig. $8 b, c)$. Because brief-access testing measures changes in licking due to taste preference, not quality per se, these results may not be directly comparable to the reaction times measured in our stop-signal task. However, combined with our evidence that mice were completely unable to detect quinine from water in the stop-signal task (Fig. 6), the data overall lead to the conclusion that mice require substantially more sampling cycles for bitter perception than other taste qualities. 
a

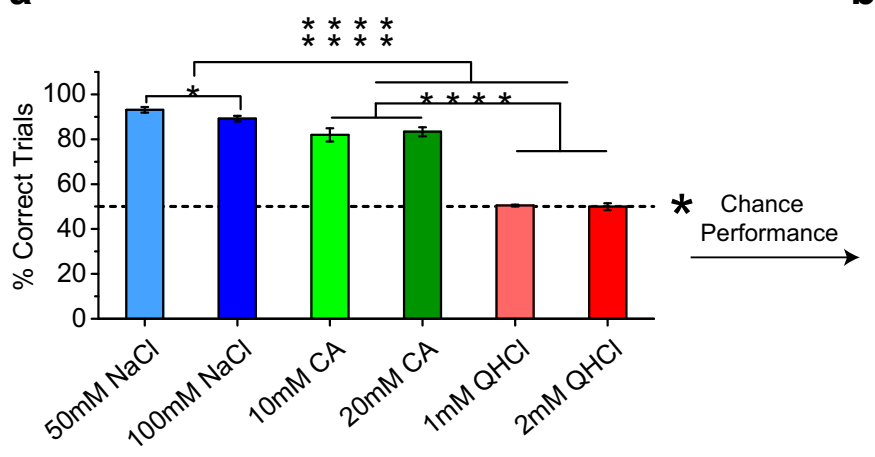

C

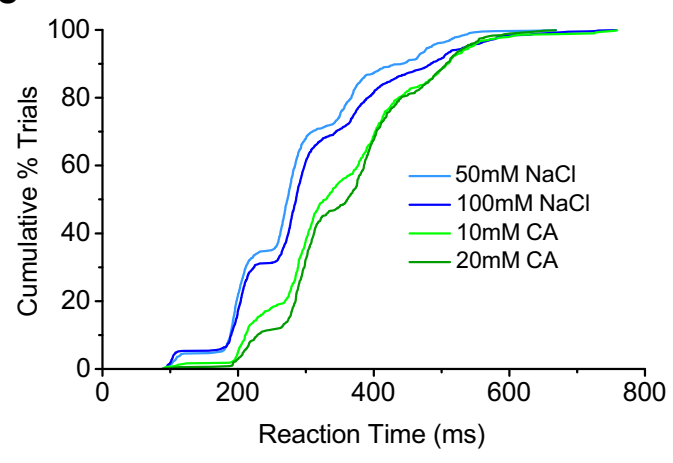

b

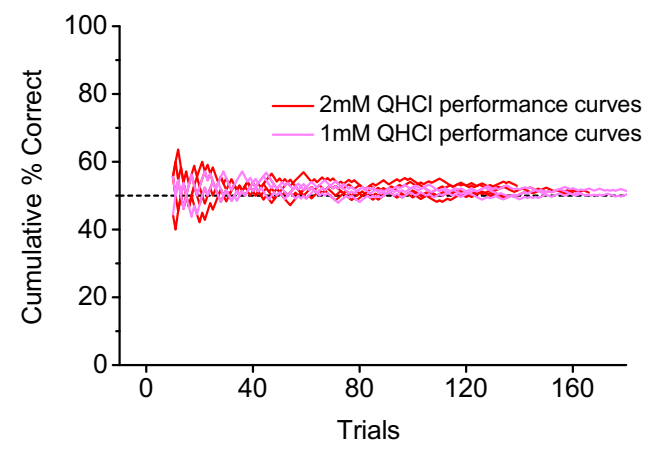

d

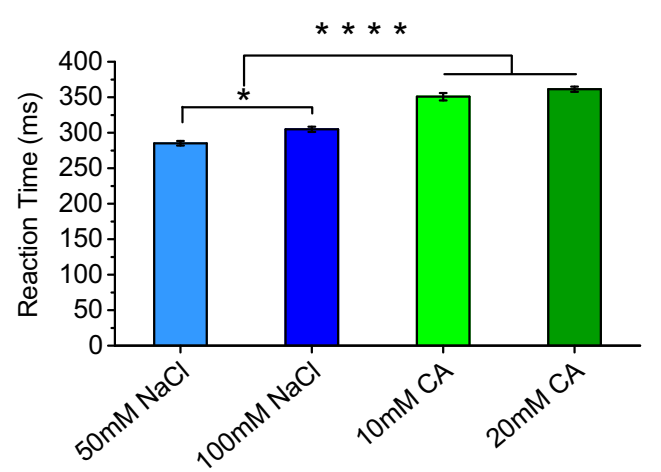

Figure 6. Mice cannot detect presence of bitter in stop-signal task. $\boldsymbol{a}$, Performance (mean \pm SEM) in detection version of the gustatory stop-signal task (water as no-stop stimulus) for individual concentrations of different taste qualities used as stop stimuli. There were small but significant differences between 50 and $100 \mathrm{~mm} \mathrm{NaCl}$ ( $p<0.01$, ANOVA) and also between salt and sour taste qualities ( $p<0.001$, ANOVA). The biggest difference in performance, however, was with bitter stimuli. Mice were unable to perform above $50 \%$ chance levels (dashed line), indicating that they could not detect the presence of 1 or 2 mm quinine in the decision phase of the stop-signal task ( $p<0.0000001$, ANOVA). Asterisks denote all comparisons with significant differences between individual taste stimuli. $\boldsymbol{b}$, Top, Example session results using $2 \mathrm{~mm}$ quinine as a stop stimulus. Similar to sessions with other taste qualities as stop stimuli, mice performed well on no-stop trials, indicating that there were no major changes in the animals' overall motivation or task participation. Licking behavior was similar for QHCl stop task compared with salt detection task ( $39 \pm 7$ ms salt LD, $43 \pm 8 \mathrm{~ms}$ QHCI LD; $64 \pm 12 \mathrm{~ms} \mathrm{salt} \mathrm{ILI,} 67 \pm 18 \mathrm{~ms} \mathrm{QHCI} \mathrm{ILI;} \mathrm{mean} \pm$ SD). Bottom, Individual cumulative performance curves for 1 and 2 mm sessions demonstrating that, throughout each session with bitter stimuli, performance of each animal hovered at chance levels ( $50 \%$, dashed line). $c$, Cumulative reaction-time distributions for different concentrations of NaCl and citric acid (CA). Similar to the results in the discrimination version of the stop-signal task, salt detection was faster than sour detection ( $p<0.0001$, AN0VA). $\boldsymbol{d}$, Comparison of reaction times for all salt and sour stimuli used in the detection task (mean \pm SEM). Asterisks denote statistical significance for each comparison.

Because mice were unable to detect a single $\sim 4 \mu$ d drop of quinine during the extended stop-signal task (1200 ms decision phase, $51.3 \pm 2.7 \%$ correct performance), the brief-access results demonstrate that, in addition to extra sampling time, mice require more stimulus volume to respond to bitter stimuli compared with salty, sweet, and sour stimuli. This led us to hypothesize a peripheral mechanism underlying the substantial difference in the timing of perception of bitter compared with other taste qualities. For the remaining experiments, we focused specifically on salt and bitter stimuli because these two qualities had the largest difference in reaction times. Taste sensory information is relayed from the oral cavity to the brainstem via three separate nerves with anatomically distinct receptive fields. These taste nerves also have well documented differences in sensitivities to various taste qualities. The chorda tympani (CT), greater superficial petrosal (GSP), and glossopharyngeal (IX) all respond robustly to salt stimuli (Shingai and Beidler, 1985; Harada et al., 1997; Sollars and Hill, 1998; Danilova and Hellekant, 2003); however, the IXth nerve is far more sensitive to bitter compounds, including quinine, than either CT or GSP (Shingai and Beidler, 1985; Danilova and Hellekant, 2003). Therefore, with the tip of the tongue innervated by CT and highly sensitive to salt, the mechanics of licking dictate that active sampling of a salt solution would stimulate this region simultaneously upon stimulus contact, whereas bitter solutions might require a significant delay to stimulate taste receptor cells in the posterior oral cavity. These posterior receptive fields could include taste buds in the anterior foliate papillae (innervated by the CT), taste buds on the soft palate (innervated by the GSP), and/or taste buds in posterior foliate papillae and in the circumvallate papilla (innervated by the IX; Spector and Travers, 2005). Such a mechanism provides a parsimonious explanation for our discrimination and detection results (Fig. 5 and Fig. 6). Interestingly, Spector and colleagues provide convincing data in rat that elimination of the IX has little effect on bitter taste perception, but does influence gape responses and unconditioned licking to bitter stimuli (King et al., 1999; Markison et al., 1999; King et al., 2000; Geran and Travers, 2011), suggesting that taste buds other than those innervated by IX carry bitter taste signals to the brain.

\section{CT nerve is required for rapid salt perception}

To test this peripheral mechanism, we cut the CT nerves bilaterally in mice that were trained in the gustatory stop-signal task. Our hypothesis was that the timing of $\mathrm{NaCl}$ perception would be 

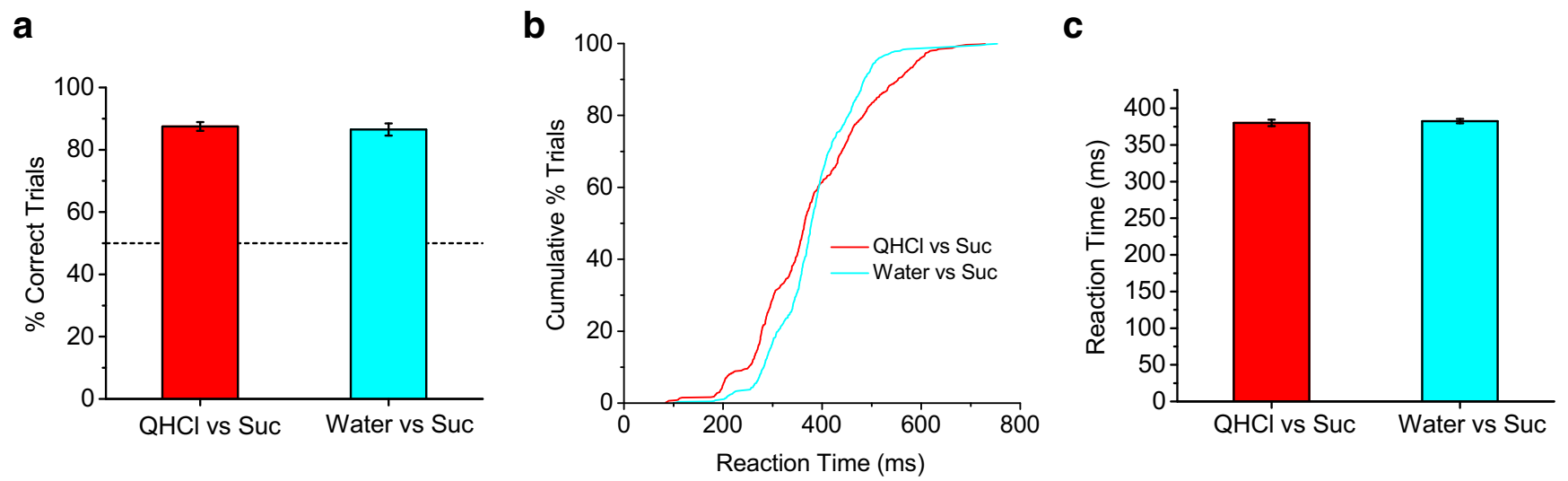

Figure 7. Mice use absence of sucrose as a stop cue during QHCl discrimination. $a$, Performance in stop-signal discrimination task with quinine (1 and 2 mm) or water as stop stimulus and 300 mm sucrose as the no-stop stimulus. Data are plotted as mean \pm SEM. No significant difference was observed. QHCl data are from mice used in Figure 5 ( $p>0.6, t$ test). Dashed line indicates $50 \%$ chance level performance. $\boldsymbol{b}$, Cumulative distributions of reaction times for quinine and water correct-stop trials. Notice the significant overlap. $\boldsymbol{c}$, Reaction-time comparison for quinine and water stop stimuli (mean \pm SEM). No significant difference was observed, indicating that mice used the lack of sucrose on quinine stop trials as a discriminatory cue instead of the presence of quinine ( $p>0.6$, $t$ test). The reaction times on correct-stop trials during quinine discrimination, therefore, provide an estimate of the speed of sucrose perception.
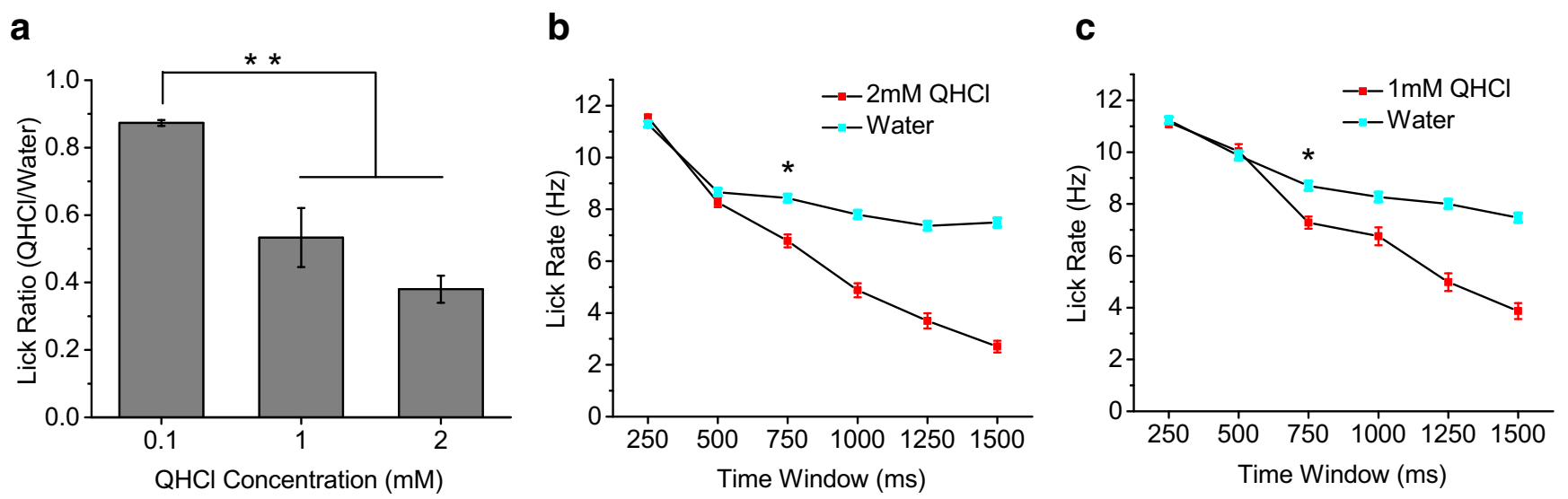

Figure 8. Brief-access test reveals that mice require $\sim 500-750 \mathrm{~ms}$ to detect bitter. $\boldsymbol{a}$, Comparison of quinine/water lick ratios during $3 \mathrm{~s}$ brief-access testing for increasing concentrations of quinine (mean \pm SEM). Mice significantly reduced licking to both 1 and 2 mm quinine compared with 0.1 mm quinine, indicating that they could detect these concentrations of quinine that were used in the stop-signal task ( $p<0.01$, ANOVA). $\boldsymbol{b}, \boldsymbol{c}$, Lick-rate comparisons for water and quinine stimuli using nonoverlapping 250 ms time windows. Data are plotted as mean \pm SEM. Mice did not begin to significantly change lick rate (denoted by asterisk) to quinine until $500-750 \mathrm{~ms}$ after stimulus contact $(p<0.00001, t$ test).

significantly longer than precut conditions, with little to no effect on the timing of bitter behavioral responses in the brief-access test version of the task. The results shown in Figures 9 and 10 are consistent with our hypothesis, showing a dramatic reduction in speed and performance of $\mathrm{NaCl}$ detection and discrimination compared with precut conditions and sham control animals $(p<$ 0.0001; Fig. 9) and no reduction in the speed of responding to bitter stimuli during brief access testing (Fig. 10). Lick ratios to quinine were also not significantly affected after CT cuts, including reductions in lick ratios between $0.1,1$ and $2 \mathrm{mM} \mathrm{QHCl}(34 \%$ vs $31 \%$ reduction at $1 \mathrm{~mm} \mathrm{QHCl}$ for precut vs CTx, $p>0.77,49 \%$ vs $45 \%$ reduction at $2 \mathrm{~mm} \mathrm{QHCl}$ for precut vs CTx, $p>0.44$; Fig. 10). Moreover, CT cuts had almost no effect on licking behavior, indicating that the deficit in performance during $\mathrm{NaCl}$ identification was sensory and not motor in origin (Fig. $9 g-i$ ).

\section{Discussion}

A novel taste-quality discrimination task in head-restrained mice was developed here to accurately capture the timing of tastequality perception during active sensing. Using this task, we demonstrated that certain taste qualities are perceived inherently faster than others and that licking, combined with the peripheral organization of the gustatory system, may set taste-qualityspecific limits on the speed of detection. Salt perception begins at the sensory-motor limits of a single lick and at a full sampling cycle faster than sour taste perception. Bitter taste perception was unique in requiring several sampling cycles and increased stimulus volume before behavioral responses appeared, clearly separating itself in time from all other taste qualities tested (for comparison, see Weiss and Di Lorenzo, 2012). Overall, the results highlight the important role that active sensing plays in shaping taste-quality perception and temporal processing of gustatory information. Although our task design did not allow us to use sucrose as a stop stimulus, we were able to estimate the time required for mice to detect the absence of sucrose by using water as a stop stimulus (Fig. 7). Our results indicate that, similar to sour, mice may require a full sampling cycle longer than salt to accurately detect the presence of sweet, but we cannot rule out that forcing mice to use reverse evidence (absence instead of presence of sucrose) to stop licking did not influence the speed of their decisions.

Recent studies using anesthetized preparations and alert animals have revealed a prominent role for dynamic temporal pro- 
a

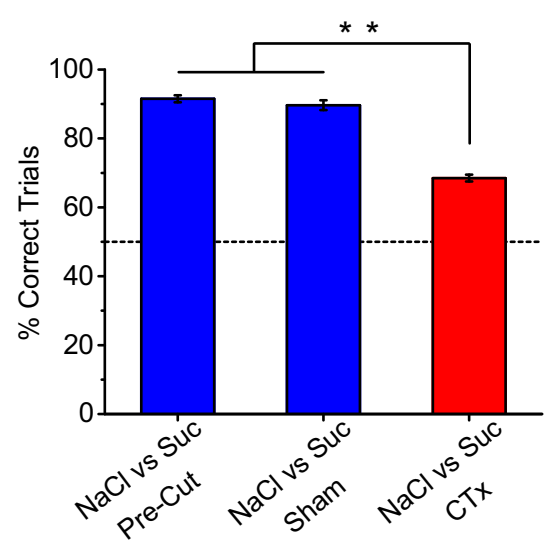

d

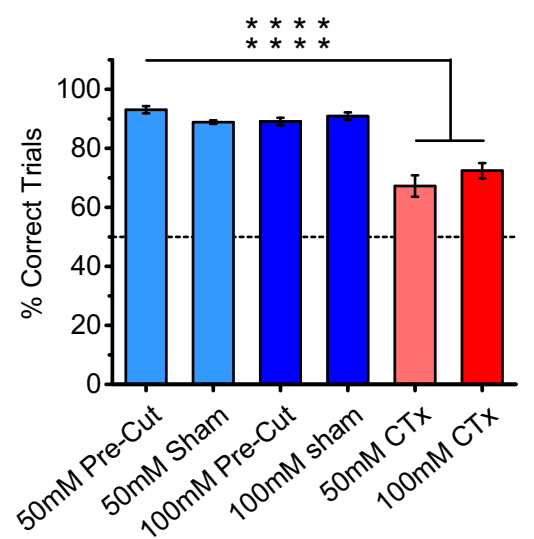

g
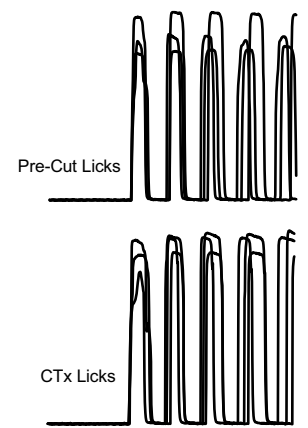

$\underline{45 \mathrm{~ms}}$ b

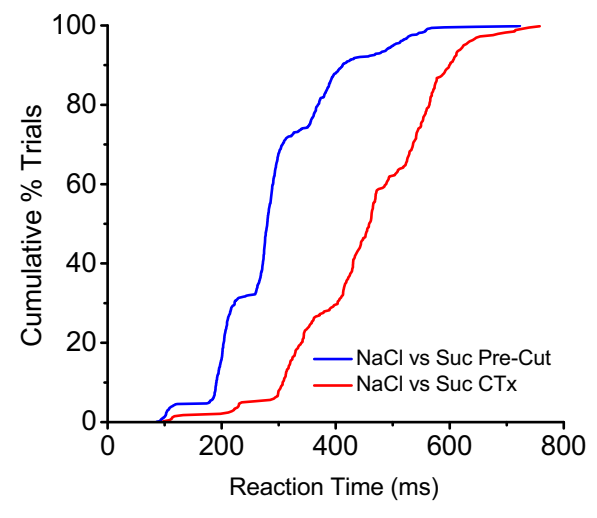

e

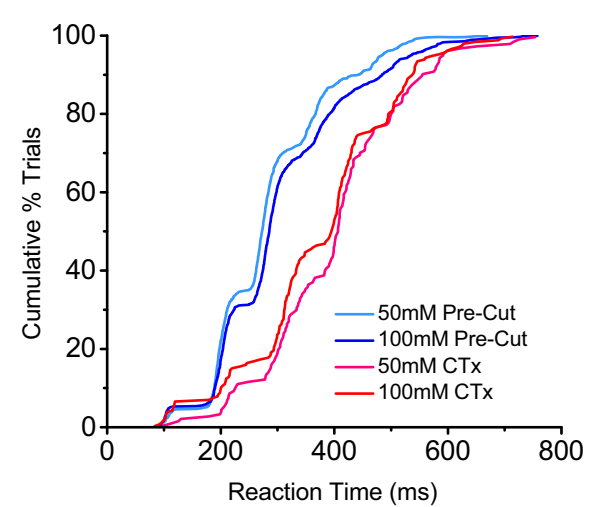

h

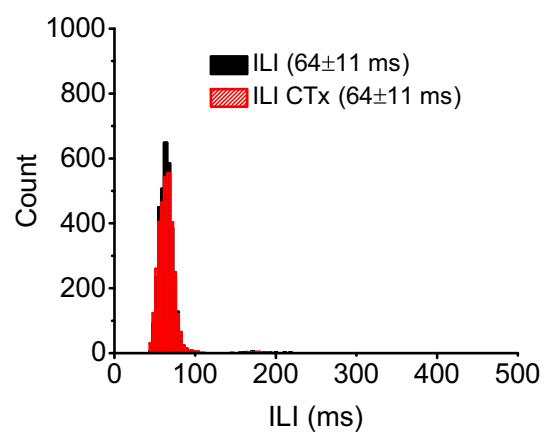

C

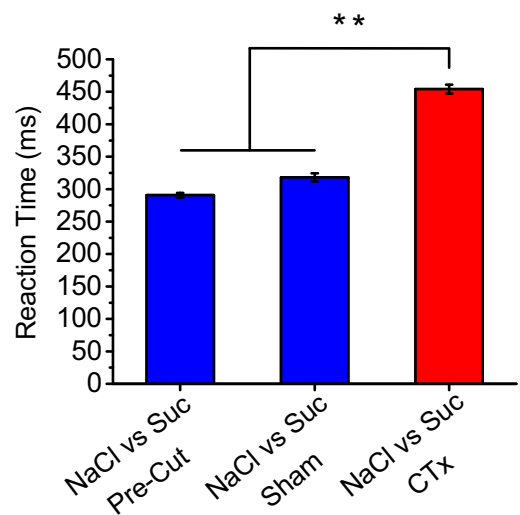

f

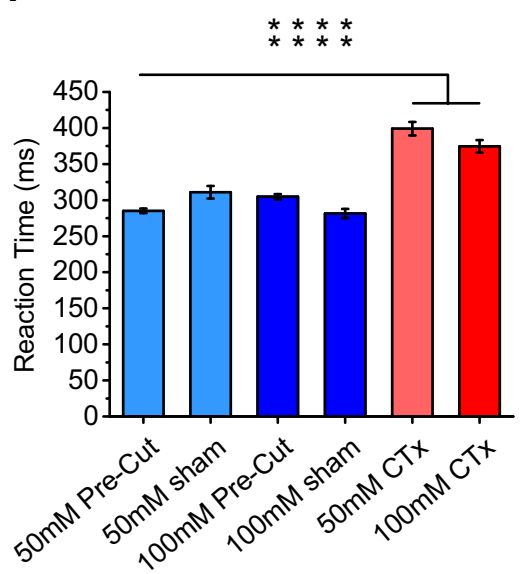

i

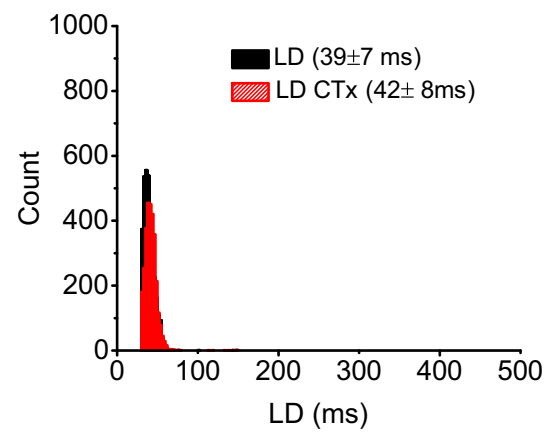

Figure 9. CTx reduces the speed of salt perception. $\boldsymbol{a}$, Performance discriminating NaCl from sucrose before and after CTx. Data plotted as mean \pm SEM. Mice showed a significant drop in performance accuracy after (Tx ( $p<0.0001$ ANOVA). Stimuli were 100 and $50 \mathrm{~mm} \mathrm{NaCl}$ and 300 and $100 \mathrm{~mm}$ sucrose. $\boldsymbol{b}$, $\boldsymbol{c}$, Cumulative distributions and average reaction times for mice discriminating $\mathrm{NaCl}$ from sucrose before and after CTx. Mice showed a significant reduction in their speed of accurate discrimination after CTx ( $p<0.00001$, ANOVA). Results in $c$ are plotted as mean \pm SEM. $\boldsymbol{d}-\boldsymbol{f}$, Similar results were found for the NaCl detection version of stop-signal task after CTx, with mice showing a significant reduction in speed of NaCl detection at all concentrations tested. Asterisks denote significant change for each individual comparison ( $p<0.0001$, ANOVA). $\boldsymbol{g}-\boldsymbol{i}$, Measurements of LD and ILI for before and after CTx showed little change (note overlap in distributions). We observed only small changes in LDs, with no changes in ILIs. Overall, the results demonstrate that the effect on speed of NaCl identification after CTx was sensory in origin and not motor.

cessing of taste information in the brain, most likely enforced by the synaptic network organization of central gustatory structures, which have led to a dynamic coding hypothesis of taste quality (Katz et al., 2002a). This study adds a new layer to the dynamic coding hypothesis, demonstrating that quality-related temporal information is actively shaped by the animal's sampling behavior at the periphery. Although the anatomical segregation and se- quential activation of receptive fields during licking likely account for much of the difference seen in reaction times between taste qualities, other sources of peripheral processing, such as transduction cascades and complex synaptic dynamics among taste receptor cells and primary afferent neurons, may also contribute (Breza et al., 2010; Roper, 2013). The results support and add important insights to previous work regarding the role of 


\section{CTx Brief-Access}

a

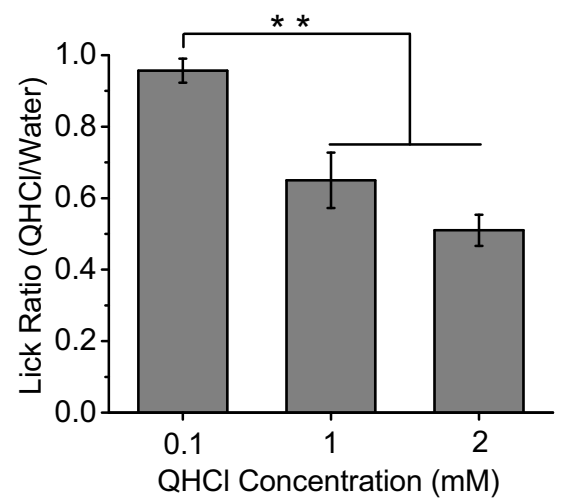

$\stackrel{0.1}{\mathrm{QHCl}} \begin{array}{cc}1 & 2 \\ & \end{array}$

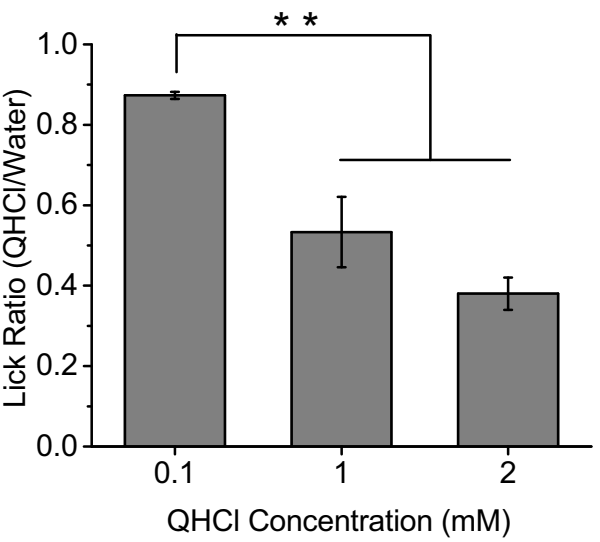

b

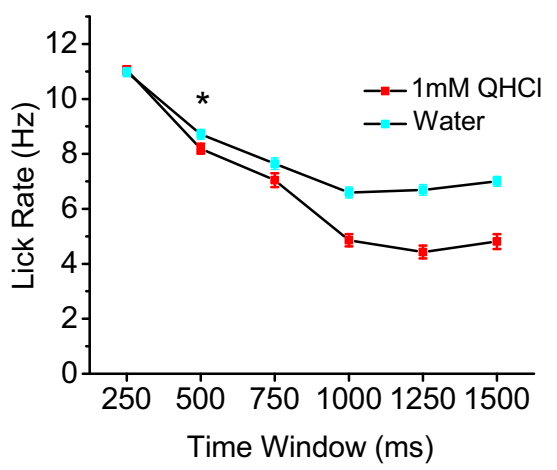

\section{Pre-Cut Brief-Access}
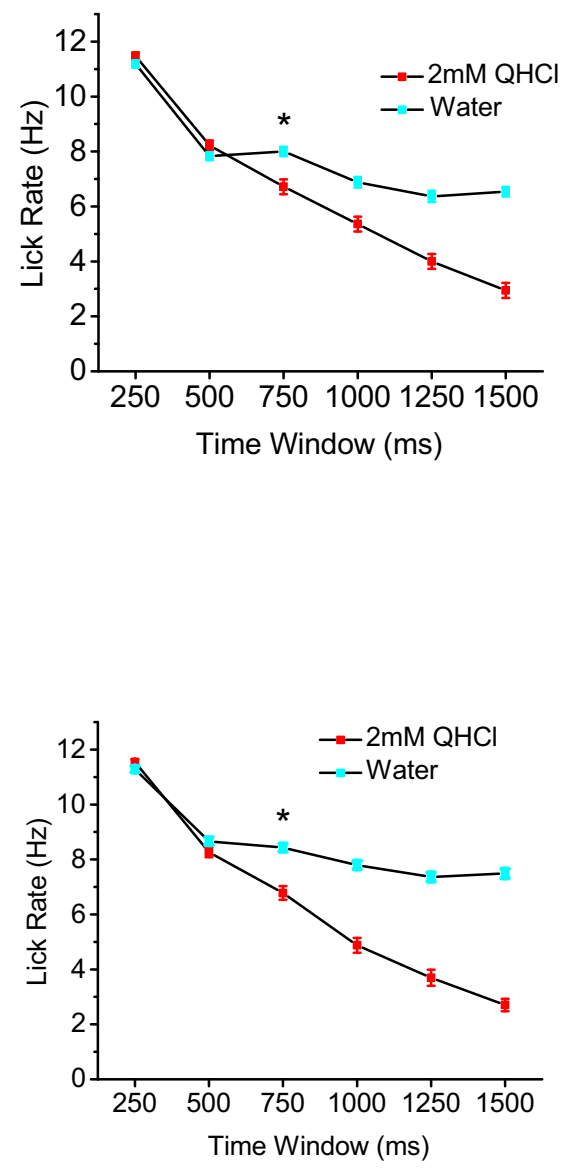

Figure 10. CTx does not slow the speed of bitter perception. $\boldsymbol{a}-\boldsymbol{c}$, Brief-access test results with bitter stimuli after CTx. Similar to precut conditions (Fig. 8), mice displayed a significant drop in licking to increasing concentrations of quinine ( $p<0.01$, ANOVA). Importantly, we observed that the timing of lick rate change relative to water was as fast or even faster in response to 1 and $2 \mathrm{~mm}$ quinine after CTx compared with precut conditions, indicating the CTx did not hinder the speed of bitter perception, consistent with our hypothesis. Results are plotted as mean \pm SEM. Asterisks indicate statistical significance at $p<0.05$. Differences in lick rates in $250 \mathrm{~ms}$ windows were compared using $t$ tests.

peripheral nerves in taste-quality discrimination, especially the unique roles that nerves serving different parts of tongue and oral cavity play in signaling specific taste qualities (Spector et al., 1990; St John and Spector, 1998).

Another important finding is our evidence that mice can identify and respond behaviorally to taste quality at the sensorymotor limits of a single lick. More than four decades have passed since Halpern and Tapper (1971) published their classic work on the timing of taste-quality perception. Since then, a number of studies have reported taste reaction times that have varied considerably, most likely due to task structure and stimulus delivery (Yoshida and Katz, 2011; Weiss and Di Lorenzo, 2012; Perez et al., 2013). The $\sim 100 \mathrm{~ms}$ reaction times measured here are remarkably fast, but it is important to recognize that these results do not imply that a complete "representation" for taste quality is contained in such a short time window. Instead, our results provide insight into when the codes for particular taste-quality categories diverge significantly enough for mice to accurately identify their difference. In addition, the results from the detection version of our task show that the onset of taste coding, relative to licking, is strongly taste-quality dependent. Because of the inherent difficulty in assigning any coding strategy to behavioral observations, we cannot conclude that temporal coding is used directly to generate the taste-quality-specific differences in the timing of decisions measured by our task. Given this constraint, however, we believe that the detection task results (i.e., the detection of the presence of specific taste qualities over water) provide a compelling argument that latency coding, with licking serving as a reference signal, may provide a robust and unique source of information regarding taste-quality identity during active sensing. In other words, whereas the $\sim 100 \mathrm{~ms}$ immediately proceeding a single lick of salt may not provide a complete representation of salt, the onset of salt coding in that window of time could provide the animal with enough information to accurately conclude that the stimulus is not sour, bitter, or sweet. Further experiments combining reaction-time tasks that can accurately capture the speed of taste guided decisions during active sampling, such as the gustatory stop-signal task, with physiological recordings will help to shed more light on the role of latency and timing in taste-quality coding.

As with a single sniff in olfaction (Uchida and Mainen, 2003; Shusterman et al., 2011), we know that significant amounts of 
information are contained within a single lick, even in central gustatory structures far removed from the mouth (Stapleton et al., 2006). Recordings from gustatory cortex of awake rats consistently show stimulus-induced responses within $100 \mathrm{~ms}$ of delivery (Katz et al., 2001, 2002b), with some studies finding sufficient information for stimulus discrimination in population responses in $<150 \mathrm{~ms}$ (Stapleton et al., 2006, 2007). The specific neural circuitry and mechanism underlying a mouse's ability to transform gustatory sensory information into a change in behavior on such a rapid time scale awaits further study. However, recent work indicating that the gustatory system does not quietly wait for the arrival of sensory evidence seems especially relevant in light of findings presented here. Multielectrode recordings in rats trained to associate auditory cues with specific taste stimuli show that these cues can activate taste-specific neurons in an anticipatory manner, speeding up their responses to gustatory stimuli (Samuelsen et al., 2012). In addition, rats can actively control the prestimulus activity of gustatory cortical neurons in a taskdependent fashion, sharpening taste selectivity and improving discriminatory coding (Yoshida and Katz, 2011). Based on this evidence for prestimulus priming of activity, it is reasonable that the decision to initialize and execute a motor command for licking may also engage these sensory networks, enabling rapid processing of relevant sensory information for decision making. Indeed, licking has been shown to synchronize activity across cortical gustatory structures during decision-making, providing "top-down" processing on incoming sensory information (Gutierrez et al., 2010). Combined with the "bottom-up" processing at the periphery shown in our results, licking may provide a crucial reference signal for coordinating the multimodal and dynamic components of gustation necessary for rapid and accurate discrimination.

Although our results show that latency coding may play a role in taste-quality detection, they also suggest a role for neural identity. Evidence for and against a spatial code for taste quality exists, but there is particularly strong evidence that bitter taste may be unique and spatially segregated from other quality representations (Travers et al., 1987; King et al., 1999; Geran and Travers, 2006; Chen et al., 2011). Our results demonstrating that bitter is the only taste quality that mice cannot detect during our rapid stop-signal task and that bilateral CT cuts produce deficits in the speed of salt discrimination with little change in bitter perception support the notion that bitter-specific information may reside in distinct nerve fibers separate from other taste qualities. Active sensing, therefore, may provide a robust mechanism to optimize the separation of taste-quality information in both the spatial and temporal coding domains. However, this does not imply that bitter taste perception is driven entirely by one specific nerve (e.g., the glossopharyngeal) or pathway. The behavioral consequences to gustatory nerve transection are not always straightforward (Spector and Glendinning, 2009), and must be interpreted with some caution. Although our results do not necessarily assign the detection of specific taste qualities solely to specific nerves, the data from CT ablation shown in Figure 9 suggest that salt perception most likely begins at the tip of the tongue, and is therefore concomitant with licking, whereas bitter perception may not begin until multiple sampling cycles have allowed stimulus access to other receptive fields beyond the anterior tongue. Regardless, the dramatic differences seen in the timing of detection between sodium and bitter from water indicate that the gustatory system may make use of latency coding (relative to licking) for accurate quality discrimination.

The gustatory stop-signal task also adds to the growing body of literature using head-restrained mouse behavioral paradigms for studying sensory processing (Komiyama et al., 2010; O'Connor et al., 2010; Smear et al., 2011). Although head restraint has been used by others for studying taste in rodents ( Nakamura and Norgren, 1993; Katz et al., 2001; Samuelsen et al., 2012), our task differs significantly in stimulus delivery and in the ability to measure taste guided decisions with high temporal resolution. In addition, the use of mice provides the application of powerful genetic approaches for cell-specific targeting and manipulation during active tasting. We anticipate that the gustatory stop-signal task in head-restrained mice will allow the application of a wider range of new tools for studying taste coding and perception in alert and discriminating animals.

\section{References}

Breza JM, Nikonov AA, Contreras RJ (2010) Response latency to lingual taste stimulation distinguishes neuron types within the geniculate ganglion. J Neurophysiol 103:1771-1784. CrossRef Medline

Carleton A, Accolla R, Simon SA (2010) Coding in the mammalian gustatory system. Trends Neurosci 33:326-334. CrossRef Medline

Chandrashekar J, Kuhn C, Oka Y, Yarmolinsky DA, Hummler E, Ryba NJ, Zuker CS (2010) The cells and peripheral representation of sodium taste in mice. Nature 464:297-301. CrossRef Medline

Chen X, Gabitto M, Peng Y, Ryba NJ, Zuker CS (2011) A gustotopic map of taste qualities in the mammalian brain. Science 333:1262-1266. CrossRef Medline

Danilova V, Hellekant G (2003) Comparison of the responses of the chorda tympani and glossopharyngeal nerves to taste stimuli in C57BL/6J mice. BMC Neurosci 4:5. CrossRef Medline

Dotson CD, Spector AC (2007) Behavioral discrimination between sucrose and other natural sweeteners in mice: implications for the neural coding of T1R ligands. J Neurosci 27:11242-11253. CrossRef Medline

Finger TE, Danilova V, Barrows J, Bartel DL, Vigers AJ, Stone L, Hellekant G, Kinnamon SC (2005) ATP signaling is crucial for communication from taste buds to gustatory nerves. Science 310:1495-1499. CrossRef Medline

Geran LC, Travers SP (2006) Single neurons in the nucleus of the solitary tract respond selectively to bitter taste stimuli. J Neurophysiol 96:25132527. CrossRef Medline

Geran LC, Travers SP (2011) Glossopharyngeal nerve transection impairs unconditioned avoidance of diverse bitter stimuli in rats. Behav Neurosci 125:519-528. CrossRef Medline

Glendinning JI, Gresack J, Spector AC (2002) A high-throughput screening procedure for identifying mice with aberrant taste and oromotor function. Chem Senses 27:461-474. CrossRef Medline

Gold JI, Shadlen MN (2007) The neural basis of decision making. Annu Rev Neurosci 30:535-574. CrossRef Medline

Grobe CL, Spector AC (2008) Constructing quality profiles for taste compounds in rats: a novel paradigm. Physiol Behav 95:413-424. CrossRef Medline

Gutierrez R, Simon SA, Nicolelis MA (2010) Licking-induced synchrony in the taste-reward circuit improves cue discrimination during learning. J Neurosci 30:287-303. CrossRef Medline

Halpern BP, Tapper DN (1971) Taste stimuli: quality coding time. Science 171:1256-1258. CrossRef Medline

Harada S, Yamamoto T, Yamaguchi K, Kasahara Y (1997) Different characteristics of gustatory responses between the greater superficial petrosal and chorda tympani nerves in the rat. Chem Senses 22:133-140. CrossRef Medline

Hayar A, Bryant JL, Boughter JD, Heck DH (2006) A low-cost solution to measure mouse licking in an electrophysiological setup with a standard analog-to-digital converter. J Neurosci Methods 153:203-207. CrossRef Medline

Heck GL, Mierson S, DeSimone JA (1984) Salt taste transduction occurs through an amiloride-sensitive sodium transport pathway. Science 223: 403-405. CrossRef Medline

Hill DL, Formaker BK, White KS (1990) Perceptual characteristics of the amiloride-suppressed sodium chloride taste response in the rat. Behav Neurosci 104:734-741. CrossRef Medline

Hill DN, Curtis JC, Moore JD, Kleinfeld D (2011) Primary motor cortex reports efferent control of vibrissa motion on multiple timescales. Neuron 72:344-356. CrossRef Medline

Johnson AW, Sherwood A, Smith DR, Wosiski-Kuhn M, Gallagher M, Hol- 
land PC (2010) An analysis of licking microstructure in three strains of mice. Appetite 54:320-330. CrossRef Medline

Katz DB, Simon SA, Nicolelis MA (2001) Dynamic and multimodal responses of gustatory cortical neurons in awake rats. J Neurosci 21:44784489. Medline

Katz DB, Nicolelis MA, Simon SA (2002a) Gustatory processing is dynamic and distributed. Curr Opin Neurobiol 12:448-454. CrossRef Medline

Katz DB, Simon SA, Nicolelis MA (2002b) Taste-specific neuronal ensembles in the gustatory cortex of awake rats. J Neurosci 22:1850-1857. Medline

King CT, Travers SP, Rowland NE, Garcea M, Spector AC (1999) Glossopharyngeal nerve transection eliminates quinine-stimulated fos-like immunoreactivity in the nucleus of the solitary tract: implications for a functional topography of gustatory nerve input in rats. J Neurosci 19: 3107-3121. Medline

King CT, Garcea M, Spector AC (2000) Glossopharyngeal nerve regeneration is essential for the complete recovery of quinine-stimulated oromotor rejection behaviors and central patterns of neuronal activity in the nucleus of the solitary tract in the rat. J Neurosci 20:8426-8434. Medline

Komiyama T, Sato TR, O'Connor DH, Zhang YX, Huber D, Hooks BM, Gabitto M, Svoboda K (2010) Learning-related fine-scale specificity imaged in motor cortex circuits of behaving mice. Nature 464:1182-1186. CrossRef Medline

MacDonald CJ, Meck WH, Simon SA, Nicolelis MA (2009) Taste-guided decisions differentially engage neuronal ensembles across gustatory cortices. J Neurosci 29:11271-11282. CrossRef Medline

Markison S, St John SJ, Spector AC (1999) Glossopharyngeal nerve transection reduces quinine avoidance in rats not given presurgical stimulus exposure. Physiol Behav 65:773-778. Medline

Nakamura K, Norgren R (1993) Taste responses of neurons in the nucleus of the solitary tract of awake rats: an extended stimulus array. J Neurophysiol 70:879-891. Medline

O'Connor DH, Peron SP, Huber D, Svoboda K (2010) Neural activity in barrel cortex underlying vibrissa-based object localization in mice. Neuron 67:1048-1061. CrossRef Medline

Oka Y, Butnaru M, von Buchholtz L, Ryba NJ, Zuker CS (2013) High salt recruits aversive taste pathways. Nature 494:472-475. CrossRef Medline

Perez IO, Villavicencio M, Simon SA, Gutierrez R (2013) Speed and accuracy of taste identification and palatability: impact of learning, reward expectancy, and consummatory licking. Am J Physiol Regul Integr Comp Physiol 305:R252-R270. CrossRef Medline

Reis PM, Jung S, Aristoff JM, Stocker R (2010) How cats lap: water uptake by Felis catus. Science 330:1231-1234. CrossRef Medline

Roper SD (2013) Taste buds as peripheral chemosensory processors. Semin Cell Dev Biol 24:71-79. CrossRef Medline

Samuelsen CL, Gardner MP, Fontanini A (2012) Effects of cue-triggered expectation on cortical processing of taste. Neuron 74:410-422. CrossRef Medline
Shingai T, Beidler LM (1985) Response characteristics of three taste nerves in mice. Brain Res 335:245-249. CrossRef Medline

Shusterman R, Smear MC, Koulakov AA, Rinberg D (2011) Precise olfactory responses tile the sniff cycle. Nat Neurosci 14:1039-1044. CrossRef Medline

Smear M, Shusterman R, O'Connor R, Bozza T, Rinberg D (2011) Perception of sniff phase in mouse olfaction. Nature 479:397-400. CrossRef Medline

Sollars SI, Hill DL (1998) Taste responses in the greater superficial petrosal nerve: substantial sodium salt and amiloride sensitivities demonstrated in two rat strains. Behav Neurosci 112:991-1000. CrossRef Medline

Spector AC, Glendinning JI (2009) Linking peripheral taste processes to behavior. Curr Opin Neurobiol 19:370-377. CrossRef Medline

Spector AC, Travers SP (2005) The representation of taste quality in the mammalian nervous system. Behav Cogn Neurosci Rev 4:143-191. CrossRef Medline

Spector AC, Schwartz GJ, Grill HJ (1990) Chemospecific deficits in taste detection after selective gustatory deafferentation in rats. Am J Physiol 258:R820-R826. Medline

Spector AC, Guagliardo NA, St John SJ (1996) Amiloride disrupts NaCl versus $\mathrm{KCl}$ discrimination performance: implications for salt taste coding in rats. J Neurosci 16:8115-8122. Medline

Stapleton JR, Lavine ML, Wolpert RL, Nicolelis MA, Simon SA (2006) Rapid taste responses in the gustatory cortex during licking. J Neurosci 26:4126-4138. CrossRef Medline

Stapleton JR, Lavine ML, Nicolelis MA, Simon SA (2007) Ensembles of gustatory cortical neurons anticipate and discriminate between tastants in a single lick. Front Neurosci 1:161-174. CrossRef Medline

St John SJ, Spector AC (1998) Behavioral discrimination between quinine and $\mathrm{KCl}$ is dependent on input from the seventh cranial nerve: implications for the functional roles of the gustatory nerves in rats. J Neurosci 18:4353-4362. Medline

Travers JB, Grill HJ, Norgren R (1987) The effects of glossopharyngeal and chorda tympani nerve cuts on the ingestion and rejection of sapid stimuli: an electromyographic analysis in the rat. Behav Brain Res 25:233-246. CrossRef Medline

Travers JB, Dinardo LA, Karimnamazi H (1997) Motor and premotor mechanisms of licking. Neurosci Biobehav Rev 21:631-647. CrossRef Medline

Uchida N, Mainen ZF (2003) Speed and accuracy of olfactory discrimination in the rat. Nat Neurosci 6:1224-1229. CrossRef Medline

Wachowiak M (2011) All in a sniff: olfaction as a model for active sensing. Neuron 71:962-973. CrossRef Medline

Weiss MS, Di Lorenzo PM (2012) Not so fast: taste stimulus coding time in the rat revisited. Front Integr Neurosci 6:27. CrossRef Medline

Yoshida T, Katz DB (2011) Control of prestimulus activity related to improved sensory coding within a discrimination task. J Neurosci 31:41014112. CrossRef Medline 